\title{
The Sensitivity of Southeast Pacific Heat Distribution to Local and Remote Changes in Ocean Properties ${ }^{\mathscr{O}}$
}

\author{
Daniel C. Jones, Emma Boland, And Andrew J. S. Meijers \\ British Antarctic Survey, NERC, UKRI, Cambridge, United Kingdom \\ GAEL FORGET \\ Department of Earth, Atmospheric, and Planetary Sciences, Massachusetts Institute of Technology, \\ Cambridge, Massachusetts \\ SIMON JOSEY \\ National Oceanography Centre, Southampton, United Kingdom \\ JEAN-BAPTISTE SALLÉE \\ Sorbonne Universités, UPMC Université, LOCEAN-IPSL, Paris, France \\ EMILY SHUCKBURGH \\ Department of Computer Science and Technology, University of Cambridge, Cambridge, United Kingdom
}

(Manuscript received 12 July 2019, in final form 14 January 2020)

\begin{abstract}
The Southern Ocean features ventilation pathways that transport surface waters into the subsurface thermocline on time scales from decades to centuries, sequestering anomalies of heat and carbon away from the atmosphere and thereby regulating the rate of surface warming. Despite its importance for climate sensitivity, the factors that control the distribution of heat along these pathways are not well understood. In this study, we use an observationally constrained, physically consistent global ocean model to examine the sensitivity of heat distribution in the recently ventilated subsurface Pacific (RVP) sector of the Southern Ocean to changes in ocean temperature and salinity. First, we define the RVP using numerical passive tracer release experiments that highlight the ventilation pathways. Next, we use an ensemble of adjoint sensitivity experiments to quantify the sensitivity of the RVP heat content to changes in ocean temperature and salinity. In terms of sensitivities to surface ocean properties, we find that RVP heat content is most sensitive to anomalies along the Antarctic Circumpolar Current (ACC), upstream of the subduction hotspots. In terms of sensitivities to subsurface ocean properties, we find that RVP heat content is most sensitive to basin-scale changes in the subtropical Pacific Ocean, around the same latitudes as the RVP. Despite the localized nature of mode water subduction hotspots, changes in basin-scale density gradients are an important controlling factor on heat distribution in the southeast Pacific.
\end{abstract}

\section{Introduction}

The Southern Ocean (SO) is an important region for the uptake, storage, and transport of heat and carbon; SO upwelling brings up water that has not seen the

Supplemental information related to this paper is available at the Journals Online website: https://doi.org/10.1175/JPO-D-19-0155.s1.

Corresponding author: D. C. Jones, dannes@bas.ac.uk surface for centuries or even millennia and is thus far out of equilibrium with surface temperature and atmospheric carbon (Sabine et al. 2004; Sarmiento et al. 2004; Lenton and Matear 2007; Ito et al. 2010; Talley 2013; Roemmich et al. 2015; Armour et al. 2016). Over the period 1861-2005, the SO, defined as the ocean south of $30^{\circ} \mathrm{S}$, is estimated to account for $43 \% \pm 3 \%$ of anthropogenic carbon dioxide uptake and $75 \% \pm 22 \%$ of heat uptake, despite only occupying $30 \%$ of global surface ocean area (Frölicher et al. 2015). The SO's ability to 
absorb and transport this disproportionately high fraction of heat and carbon comes in part from a balance between powerful overlying westerly winds, strong buoyancy fluxes, and internal dynamics that maintains steeply tilted surfaces of constant density and localized pools of weakly stratified water (Russell et al. 2006). These pools of weakly stratified water, referred to collectively as Subantarctic Mode Water (SAMW), are refreshed by localized wintertime deep convection that occurs just north of the Antarctic Circumpolar Current (ACC) (Speer et al. 2000; Hanawa and Talley 2001; Lumpkin and Speer 2007; Talley 2008; HerraizBorreguero and Rintoul 2011; Speer and Forget 2013). The processes of lateral induction, eddy-induced transport, and advection via the mean flow subduct the SAMW into the subsurface ocean at a rate that varies across interannual and decadal time scales (Karsten and Marshall 2002; Sallée et al. 2010; Sallée and Rintoul 2011; Sallée et al. 2012; Liu and Huang 2012). Together with the denser and relatively fresher Antarctic Intermediate Water (AAIW), SAMW ventilates the subtropical thermocline on time scales of decades to centuries (Iudicone et al. 2007; Sallée et al. 2010; Cerovečki et al. 2013; Jones et al. 2016). Here, ventilation refers to the broad set of processes by which atmospheric and surface ocean properties are able to affect subsurface ocean properties. Ventilation is driven in part by the formation, subduction, and destruction of water masses and can be considered a consequence of the ocean's global overturning circulation (Marshall and Speer 2012; Cerovečki and Mazloff 2016).

SAMW and AAIW both display complex patterns of decadal variability. In the Western Pacific, decadal-scale surface warming and/or freshening at high-latitude SAMW and AAIW subduction sites can lead to cooling and freshening along isopycnals in the subsurface (Johnson and Orsi 1997). Decadal trends in SAMW temperature and salinity display complex spatial variability; in recent decades, both the SAMW and AAIW have become warmer and saltier in the South Atlantic but cooler and fresher in the South Atlantic (Katsumata and Fukasawa 2011). The AAIW core (its salinity minimum) has warmed and shoaled overall, with small salinity trends whose sign varies by region (Schmidtko and Johnson 2012). Decadal trends of SAMW and AAIW properties are consistent with an amplification of the global hydrological cycle and broadscale surface warming (Helm et al. 2010; Durack and Wijffels 2010). The spatial and temporal complexity of these SAMW and AAIW trends suggests that we will need a full fourdimensional description of the sensitivity of ocean structure in order to make robust projections of potential future ocean states.
Regional differences in subduction, ventilation, and the properties of the ventilated subsurface can impact (i) the sequestration of anthropogenic heat and carbon into the subsurface thermocline and (ii) the supply of nutrients to low latitudes via the overturning circulation (Sarmiento et al. 2004; Sabine et al. 2004; Khatiwala et al. 2009; Ito et al. 2010; Roemmich et al. 2015). The regionally specific nature of subduction and ventilation, and how those localized characteristics affect the distribution of heat, carbon, and nutrients in the ocean, is an active area of oceanographic study (Cerovečki et al. 2013; Jones et al. 2016). Despite these efforts, we still have relatively little knowledge on how regional variations in ocean state variables (e.g., temperature, salinity) and surface forcing can ultimately impact the properties of the ventilated subsurface. Advancements in this area may be especially helpful for improving projections of future ocean states, as changes in the Southern Ocean forcing-subduction-ventilation mechanism are expected to have a considerable impact on future climate (Cessi and Otheguy 2003; Downes et al. 2009; Lovenduski and Ito 2009; Morrison et al. 2011; Sallée et al. 2012).

To quantify how regional variations in ocean state variables may affect the heat distribution in the ventilated subsurface ocean, we perform a set of adjoint sensitivity experiments using an observationally constrained, physically consistent state estimate. First, we identify the recently ventilated subsurface ocean using a combination of physical state variables (e.g. potential vorticity, density, mixed layer depth) and numerical passive tracer distributions that track ventilation pathways from the surface into the subsurface. Our method for identifying the recently ventilated subsurface treats ventilation as a general process that may affect many different water masses, in contrast to approaches that consider one particular water mass (e.g., SAMW). We focus our attention on the eastern Pacific because it features an especially efficient export pathway of water from the surface ocean into the subsurface thermocline, as measured by numerical passive tracer experiments (Jones et al. 2016). For convenience, we refer to the recently ventilated subsurface eastern Pacific as the RVP and the heat content of the RVP as RVPh. Although there is overlap between the two, we note that the RVP is more general than the region occupied by SAMW or any other particular water mass. Once we have identified the RVP, we perform a set of adjoint sensitivity experiments using, for consistency, the same numerical model setup that we used for the passive tracer experiments. Our adjoint model produces linear, 
time-evolving sensitivity maps, allowing us to identify locations and time scales where hypothetical anomalies could potentially impact the heat distribution in the ventilated subsurface, as revealed by the heat content of the fixed-volume RVP. Although we do not use this framework here, the sensitivity fields can roughly be interpreted as optimal linear perturbations, that is, perturbations with the largest possible impact on $\mathrm{RVPh}$, within the linear framework of the adjoint model [see a related but not identical example in Sévellec and Fedorov (2015)].

This paper is structured as follows: in section 2, we describe the ECCOv4 model setup, the design of our numerical tracer release experiments, and the design of our adjoint sensitivity experiments. In section 3, we examine the results of the tracer experiments in order to define the RVP, which is the control volume for our adjoint sensitivity experiments. In section 4 , we examine the time-evolving sensitivities of RVPh to changes in temperature and salinity, decomposed into changes at constant density (i.e., kinematic sensitivities) and changes with varying density (i.e., dynamic sensitivities). In section 5, we discuss factors that should be considered when comparing our results with other studies. Finally, in section 6 , we summarize our results and conclusions.

\section{Methods}

In this section, we describe the observationally constrained global ocean model setup (section 2a), the design of our numerical passive tracer experiments used to define the RVP (section $2 b$ ), and the design of our adjoint sensitivity experiments (section $2 \mathrm{c}$ ).

\section{a. Global ocean model setup}

We use the modeling setup associated with ECCOv4 (release 2, hereafter ECCOv4-r2 or just ECCOv4). ECCOv4 is a state estimate, meaning that it has been adjusted to minimize the misfits between the model state and a suite of observations from various sources over the time period 1992-2011 (e.g., Argo float temperature and salinity profiles, ship hydrography, satellite altimetry). The model's initial conditions, surface forcing fields, and mixing parameters were iteratively adjusted in order to reduce model-data misfit. Because no artificial sources or sinks of heat were used in the ocean subsurface, ECCOv4 features closed budgets of heat, salt, and volume. The model setup is available for download on GitHub (https://github.com/gaelforget/ECCOv4) as an instance of the open source MIT General Circulation Model (MITgcm, http://mitgcm.org/, also available on GitHub). We briefly describe the relevant features of the ECCOv4 setup below; a more thorough description is available in Forget et al. (2015a) and references therein.

ECCOv4 is a global ocean model that uses a latitudelongitude-cap (LLC) grid. Its horizontal grid spacing ranges from around $40-50 \mathrm{~km}$ at high latitudes up to roughly $110 \mathrm{~km}$ at the equator. It features parameterized diffusion, including both diapycnal and isopycnal components, simple convective adjustment, and the Gaspar-Gregoris-Lefevre (GGL) mixed layer turbulence closure scheme (Gaspar et al. 1990). To represent the along-isopycnal effect of unresolved eddies, Forget et al. (2015a) used a bolus transport parameterization (Gent and McWilliams 1990). Although the horizontal resolution of ECCOv4 is relatively coarse (roughly $1^{\circ}$ ), its mixing properties are in good agreement with observations, as indicated by a comparison of simulated ECCOv4 oxygen distribution and World Ocean Atlas 2013 (Forget et al. 2015b, their Fig. 4). This agreement is thanks in part to the use of optimized, spatially varying turbulent transport coefficients. ECCOv4 features fully interactive dynamic sea ice, so that buoyancy and mass fluxes at the sea surface are calculated based on the thermodynamic balance of Losch et al. (2010). Open ocean rain, evaporation, and runoff simply carry (advect through the free surface) the local SST and a salinity value of zero, and runoff is provided by a monthly climatology (Fekete et al. 2002). ECCOv4 calculates buoyancy, radiative, and mass fluxes using the bulk formulae of Large and Yeager (2009) with 6hourly ERA-Interim reanalysis fields (Dee et al. 2011) as a "first guess" for the forcing fields. Specifically, we use wind stress, 2-m air temperature, 2-m specific humidity, wind speed, downward longwave radiation, and downward shortwave radiation as model inputs. These atmospheric state fields have been iteratively adjusted by the state estimation process in order to minimize model-data misfits. The ECCOv4-r2 setup that we use here does not use surface salinity restoring. For additional validation information, see Forget et al. (2015a). For calculations relevant to mode water formation and distribution in ECCOv4, see Speer and Forget (2013).

\section{b. Design of the numerical passive tracer release experiments}

Generally, on a selected time scale (e.g., 1, 10 years), we can consider the volume of the ocean that has been affected by near-surface properties (e.g., the temperature and salinity characteristics of the mode water formation regions) as having been ventilated via advection, diffusion, and mixing. In terms of an operational definition, the ventilated subsurface ocean can be identified using physical state variables, tracer distributions, or a combination of the two. Luyten et al. (1983) showed 

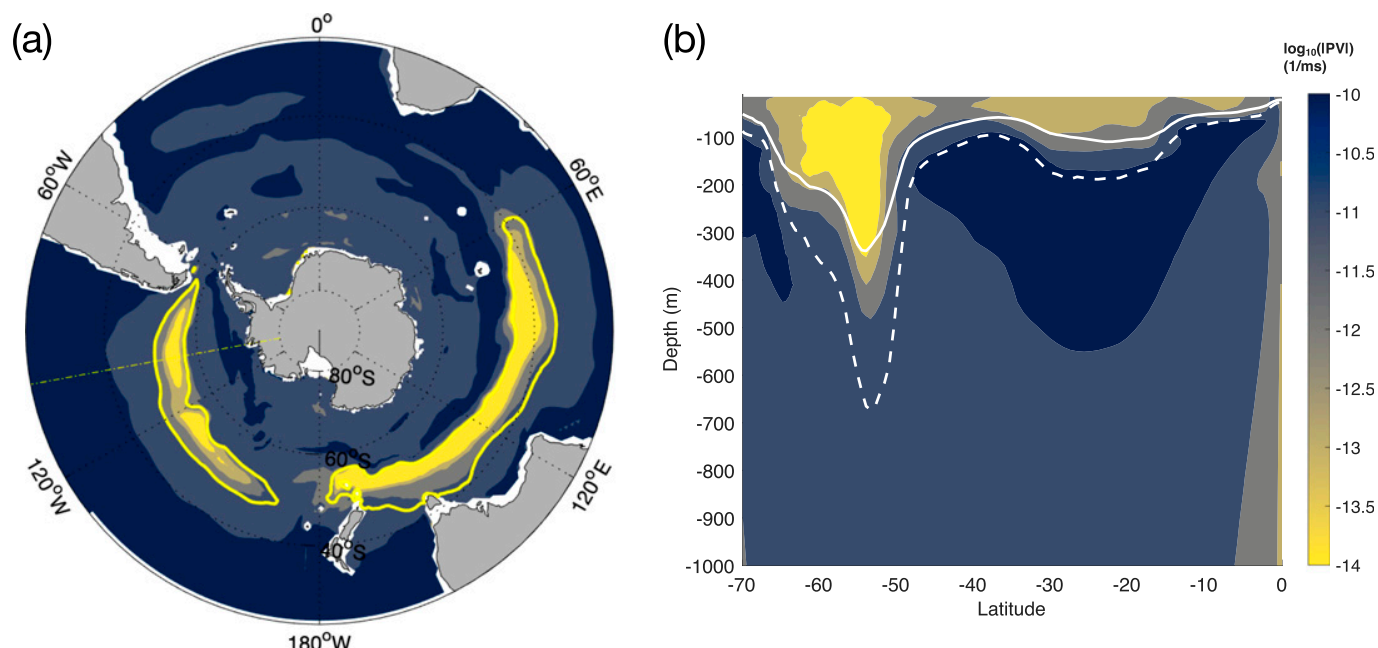

FIG. 1. Southern Ocean potential vorticity $\left(\mathrm{m}^{-1} \mathrm{~s}^{-1}\right)$ and mixed layer depth. (a) Shown are median values of annual minimum $\log _{10}(|\mathrm{PV}|)$ across the years 1992-2011 as a section through $z=300 \mathrm{~m}$. The yellow contour indicates a section through the median mixed layer mask at $z=300-\mathrm{m}$ depth, and the yellow dot-dash line indicates the location of the section in (b). (b) Section of median values of annual minimum $\log _{10}(|\mathrm{PV}|)$ across the years 1992-2011 at $100.5^{\circ} \mathrm{W}$, with ensemble median values for the annual mean (solid white line) and August-October (ASO) mean (dashed white line) mixed layer depths.

that, in a simple, inviscid, analytical model, pathways of potential vorticity $(\mathrm{PV})$ can be used to separate the ventilated thermocline from the unventilated thermocline and also to separate regions of weak stratification from regions of strong stratification. This result helps justify the use of potential vorticity as a "dynamical tracer" that indicates thermocline ventilation pathways. Alternatively, one can derive ventilation pathways using the observed distributions of tracers such as tritium, helium-3, and chlorofluorocarbons, which are carried into the subsurface by both advection along ventilation pathways and by isopycnal and diapycnal mixing (Musgrave 1990; Speer and Tziperman 1992; Primeau and Holzer 2006). In the subsurface, diapycnal mixing contributes to the erosion of water masses by homogenizing their properties across density surfaces (Trossman et al. 2012). In combination with PV and tracer considerations, the ventilated subsurface is generally considered to be located below the mixed layer, isolated from immediate contact with the surface. In this study, we use a combination of physical state variables (e.g., PV, mixed layer depth, density) and numerical passive tracer release experiments to identify the recently ventilated subsurface ocean in ECCOv4-r2, described in detail below.

First, we use stratification (PV) and mixed layer depth (MLD) to identify the Southern Ocean regions that tend to ventilate the subsurface thermocline (Fig. 1). We calculate $\mathrm{PV}=f \rho_{0}^{-1} d \rho / d z$, where $f=2 \Omega \sin (\phi)$ is the Coriolis parameter and $\rho_{0}$ is the reference density, and we calculate mixed layer depth using a criterion based on the density change associated with a temperature variation of $\Delta T=0.8^{\circ} \mathrm{C}$ (Kara et al. 2000). For each year between 1996 and 2001, we calculate the June-August (JJA) mean PV and both the JJA mean and annual maximum MLD, and we use these values with a set of criteria to construct a "mixed layer mask" for that year. Specifically, for a grid cell to be included in the mixed layer mask for a given year, it must

1) be within the annual maximum mixed layer and

2) be at a latitude and longitude where one or both of the following conditions are satisfied:

(i) the JJA mean $|\mathrm{PV}|$ at the base of the JJA mean mixed layer must be less than $10^{-10.5} \mathrm{~m}^{-1} \mathrm{~s}^{-1}$, or

(ii) the JJA mean mixed layer must be greater than $300 \mathrm{~m}$.

These relatively weak conditions ensure that we target likely ventilation pathways without being overly prescriptive.

We perform six different tracer release experiments (one for each starting year between 1996 and 2001). For each experiment, we initialize passive tracer within the corresponding year's mixed layer mask on 1 January; our method of initializing tracer above the maximum mixed layer for the release year ensures that variation associated with seasonal release timings are minimal. We integrate the tracer equations in "online" mode for 10 years, that is, we explicitly solve the momentum, buoyancy, and tracer equations at the same time. 
Note that although the bulk of the tracer used to define the RVP originates in the Pacific, a smaller fraction also comes from the Indian sector. The 10-yr time scale of the experiments allows a large fraction of weakly stratified water to subduct into the subsurface (Jones et al. 2016), and using a 10-yr time scale also allows us to carry out a suite of passive tracer and adjoint sensitivity runs within the 20-yr observationally constrained time period of ECCOv4. We then use the annual mean tracer distribution after 10 years of model integration to map out the ventilation pathways. See section 3 for more details and results.

\section{c. Design of the adjoint sensitivity experiments}

An adjoint model is a tool for sensitivity analysis; all other applications derive from there (Errico 1997). Adjoint methods can be used to construct state estimates (e.g., the ECCOv4 state estimate used in this paper) via the iterative optimization of model initial conditions, model parameters, and surface forcing (collectively called the "controls"), guided by gradients or sensitivities that are calculated by an adjoint model. In such applications, the sensitivities indicate how one needs to adjust the controls in order to reduce the cost function, which is a measure of modeldata misfit over the duration of the model run. This method enables objective, physically consistent, and efficient model optimization that would otherwise require considerable ad hoc parameter tuning and/or the introduction of artificial sources or sinks of heat and salt into the subsurface.

More generally, adjoint methods also enable us to carry out efficient and comprehensive sensitivity studies, such as the one presented in this manuscript. In a traditional "forward" perturbation experiment, the experimenter introduces a perturbation into the model (e.g., a change in the initial temperature pattern) and examines the effect on some quantity of interest (e.g., $\mathrm{RVPh}$ ). Using this method, the experimenter cannot feasibly determine if the perturbation they selected is the ideal or optimal one (i.e., the one with the largest effect on RVPh) without performing a very large number of numerical experiments. By contrast, in an adjoint sensitivity experiment, the experimenter selects a quantity of interest (e.g., annual mean $\mathrm{RVPh}$ ) and uses an adjoint approach to calculate gradients or sensitivities. The sensitivity fields indicate the perturbations with the largest possible linear impact on $\mathrm{RVPh}$. For examples of adjoint sensitivity experiments, see Verdy et al. (2014), Sévellec and Fedorov (2015), Jones et al. (2018), and many others. We refer the reader to these works for a more thorough and general description to adjoint modeling (e.g., Thacker and Long 1988; Marotzke et al. 1999b; Heimbach 2008; Mazloff et al. 2010; Griewank and
Walther 2012; Verdy et al. 2014; Forget et al. 2015a; Fukumori et al. 2015; Jones et al. 2018).

We perform a set of such adjoint sensitivity experiments in order to examine the sensitivity of RVPh to subsurface ocean properties. The objective function is defined as the annual- and volume-mean RVPh:

$$
\tilde{J}=\frac{1}{V \Delta t} \int_{V} \int_{\Delta t} \rho_{0} c_{p} \theta(\mathbf{r}, t) d t d V
$$

where $\rho_{0}$ is the reference density, $c_{p}$ is the heat capacity of seawater, $\theta$ is the potential temperature, $\mathbf{r}$ is the position vector, $t$ is the time, $V$ is the control volume, and $\Delta t$ is the time period of the integration. For convenience, we scale $\tilde{J}$ by the constant $\rho_{0} c_{p}$, so $\mathrm{RVPh}=J=\tilde{J} / \rho_{0} c_{p}$, meaning that $\mathrm{RVPh}$ has units of degrees Celsius $\left({ }^{\circ} \mathrm{C}\right)$.

We compute an ensemble of six adjoint sensitivity experiments, with the objective function defined over the last year of each run, that is, from 1 January to 31 December, with objective function years ranging from 2006 through 2011. Each experiment spans a minimum of 15 years, up to a maximum of 20 years. We allow the RVP to vary by ensemble member based on the results of the passive tracer experiments. Our ECCOv4 adjoint model calculates the sensitivities of these objective functions to a set of independent variables, including temperature $(\partial J / \partial T)$ and salinity $(\partial J / \partial S)$; the sensitivity fields vary with space (latitude, longitude, depth) and time. We use 14-day averaged sensitivity fields throughout.

\section{Identifying the recently ventilated subsurface ocean}

We use a six-member ensemble of passive tracer experiments with release years ranging from 1996 to 2001 to identify the RVP in ECCOv4. The ensemble mean, annual mean tracer distribution after 10 years of integration (Fig. 2) highlights the ventilation pathways from the Southern Ocean mixed layer into the subsurface thermocline.

The normalized tracer distribution features several cores, that is, local maxima with some degree of spatial coherence across latitudes and longitudes (Animation $\mathrm{S} 1$ in the online supplemental material). In the Atlantic sector, we find a core below the 1992-2011 maximum MLD in the subtropical latitudes (roughly between $30^{\circ}$ and $10^{\circ} \mathrm{S}$ ) that drifts southward before merging with a broad pattern that stretches from the Weddell Sea, across the ACC, and into the subtropics (Fig. 2a). The approximately zonal Atlantic distribution bears the imprint of the convergence of the Brazil Current and the ACC. In the Indian sector, the tracer distribution is 
(a)

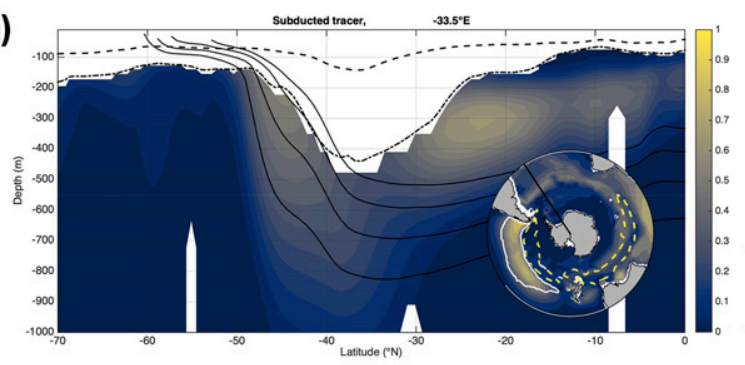

(c)

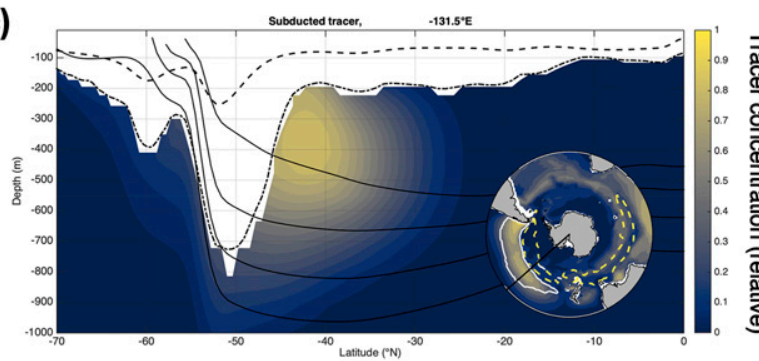

(b)

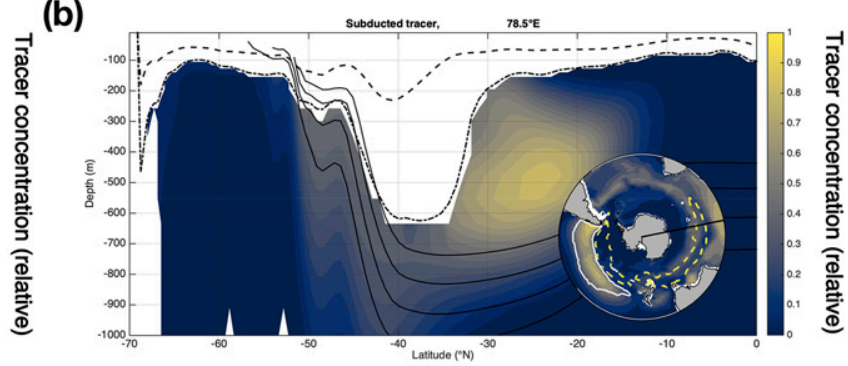

(d)

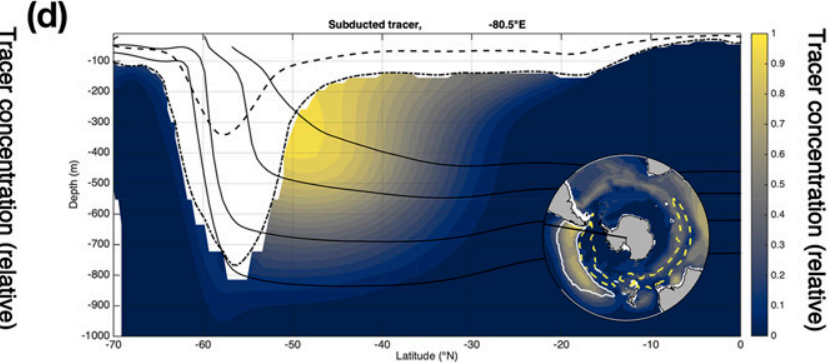

FIG. 2. Defining the recently ventilated subsurface. Shading indicates the ensemble mean, annual mean tracer after 10 years of transport. Values have been normalized by the maximum value. Also shown is the mean mixed layer depth (dashed lines) and maximum mixed layer depth (dash-dot lines) over the length of the 10-yr simulation. Solid lines indicate potential density surfaces (from $\sigma_{0}=26.9 \mathrm{~kg} \mathrm{~m}^{-3}$ to $\sigma_{0}=27.2 \mathrm{~kg} \mathrm{~m}^{-3}$, spaced every $0.1 \mathrm{~kg} \mathrm{~m}^{-3}$ ). Tracer above the maximum mixed layer has been discarded. Although we discard the tracer lighter than $\sigma_{0}=26.9 \mathrm{~kg} \mathrm{~m}^{-3}$ when defining the RVP, we kept this tracer in the figure for visualization purposes. Inset figures are columnintegrated tracer histograms, which are normalized by the maximum column-integrated value, after discarding the tracer above the maximum mixed layer, along with a section through the ensemble median mixed layer mask at $z=300$-m depth (yellow dashed contours) and a section through the ensemble median ventilated water mask at $z=553 \mathrm{~m}$ (white solid contour). Sections are shown for (a) $33.5^{\circ} \mathrm{W}$, (b) $78.5^{\circ} \mathrm{E}$, (c) $131.5^{\circ} \mathrm{W}$, and (d) $80.5^{\circ} \mathrm{W}$.

influenced by the Agulhas Current and the broader circulation of the South Indian Gyre that is characterized by relatively shallow overturning in density space; here, we find the core of the distribution at roughly $500 \mathrm{~m}$ and densities lighter than the $\sigma_{0}=26.9 \mathrm{~kg} \mathrm{~m}^{-3}$ density surface (Fig. 2b). In the Pacific sector, we find relatively large values throughout the entire South Pacific Gyre (SPG), with two distinct cores. The core of the distribution in the western SPG is found at densities lighter than $\sigma_{0}=26.9 \mathrm{~kg} \mathrm{~m}^{-3}$ and is affected by tracer that subducts in the Indian sector, whereas the core of the distribution in the eastern SPG largely straddles the $\sigma_{0}=26.9 \mathrm{~kg} \mathrm{~m}^{-3}$ line and is relatively less affected by tracer that subducts in the Indian sector (Figs. 2c,d). High tracer concentrations in the eastern region of the SPG highlights the relatively efficient eastern Pacific export pathway that was previously identified in highresolution simulations (Jones et al. 2016, Fig. 8d).

To define the RVP, we use the annual mean tracer concentrations after 10 years of transport and some additional physical and geographical criteria, selecting grid cells that satisfy the following four conditions:

- be located below the maximum mixed layer over the entire ECCOv4-r2 period (i.e., 1992-2011),
- tracer concentration is at least $10 \%$ of the global ocean maximum value,

- be located in the southeast Pacific, between $170^{\circ}$ and $60^{\circ} \mathrm{W}$ and between $60^{\circ}$ and $20^{\circ} \mathrm{S}$, and

- potential density is greater than or equal to $\sigma_{0}=$ $26.9 \mathrm{~kg} \mathrm{~m}^{-3}$.

The $\sigma_{0}=26.9 \mathrm{~kg} \mathrm{~m}^{-3}$ surface delineates lighter waters from waters that are at least as dense as the SAMW. The resulting RVP for any given release year is a threedimensional volume with a lateral imprint that varies with depth (Figs. 3 and 4). Between roughly 300 and $500 \mathrm{~m}$ (Figs. $3 \mathrm{a}-\mathrm{c}$ ), the areal extent of the RVP changes with depth and sits largely in the southeast Pacific, north of the regions with deep mixed layers. The structure of the RVP at these depths reflects the subduction and ventilation pattern associated with the eastern Pacific export pathway (Jones et al. 2016). Between roughly 500 and $700 \mathrm{~m}$ (Figs. 3d,e), the RVP reaches its maximum areal extent, covering a large fraction of the SPG.

\section{The RVP is more general than SAMW}

Although the RVP has considerable overlap with the density ranges associated with SAMW, it is more general than SAMW alone. Our passive tracers ventilate a 

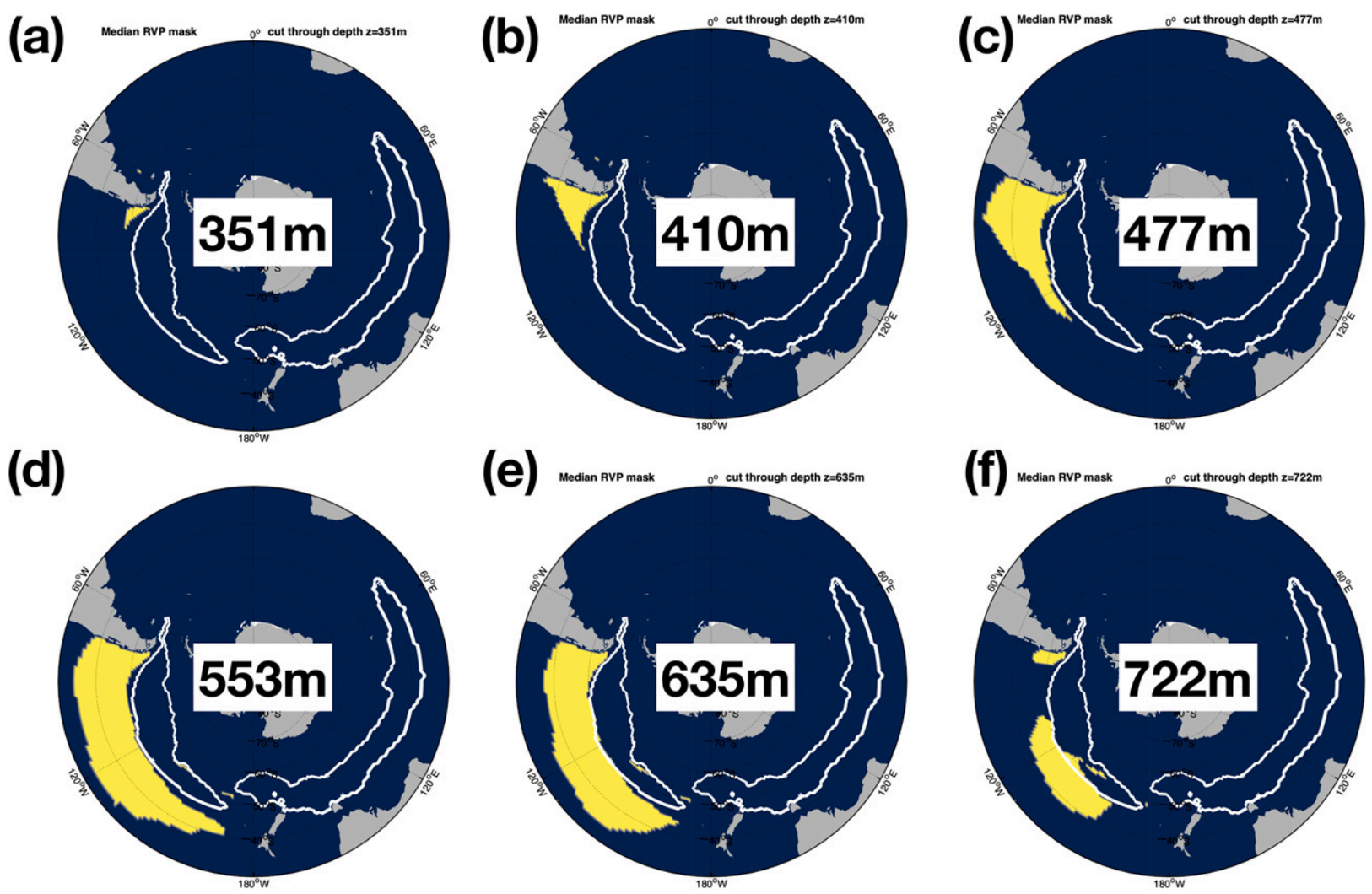

FIG. 3. Vertical structure of the ensemble median RVP. Yellow regions are included in the RVP. A section through the ensemble median mixed layer mask at roughly $300 \mathrm{~m}$ is shown for reference (white solid contours).

wide range of water masses, including SAMW, AAIW, and the lightest part of the Circumpolar Deep Water (CDW). In this way, our RVP approach is broader than an approach focused on a particular density range, in that it allows us to consider a wider range of ventilated water mass types than SAMW alone. Because RVPh is the heat content of a fixed volume, $\mathrm{RVPh}$ is a measure of the heat distribution in the target region, as RVPh may be affected by both isopycnal heave and by changes in properties along isopycnals. RVPh may have different sensitivities than the SAMW heat content, which may be affected by changes in the volume of SAMW and/or changes in the properties of water in the SAMW density range. We further explore this distinction in section 5.

Having defined the RVP in ECCOv4, we can now perform a set of adjoint sensitivity experiments using the adjoint capability of the ECCOv4 model setup.

\section{Sensitivities of subsurface heat content to local and remote anomalies}

In this section, we examine the sensitivity of RVPh to changes in temperature and salinity, decomposed into changes at constant density (i.e., kinematic sensitivities) and changes with varying density (i.e., dynamic sensitivities). In section $4 a$, we show how sensitivities to temperature and salinity perturbations can be cast in terms of kinematic and dynamic sensitivities. In section $4 \mathrm{~b}$, we investigate the spatial and temporal structure of the kinematic sensitivities, focusing on both the subsurface and the surface. Finally, in section $4 c$, we examine the spatial and temporal structure of the dynamic sensitivities, including regional patterns in the subsurface and at the surface. In this analysis, we use the time-variable $-0.25-\mathrm{m}$ ECCOv4 sea surface height contour as a proxy for the Subantarctic Front (SAF) that roughly divides the Southern Ocean into two regions-one dominated by gyre-like circulation and another region dominated by the circumpolar flow associated with the ACC (Kim and Orsi 2014).

\section{a. Defining kinematic and dynamic sensitivities}

Following Marotzke et al. (1999b) and Jones et al. (2018), we decompose the adjoint sensitivity fields into sensitivities to changes that propagate along isopycnals (i.e., kinematic) and sensitivities to changes in density (i.e., dynamic). Writing the objective function in terms of density and temperature $J=J[\rho(T, S), T]$ allows us to write the sensitivities as follows: 

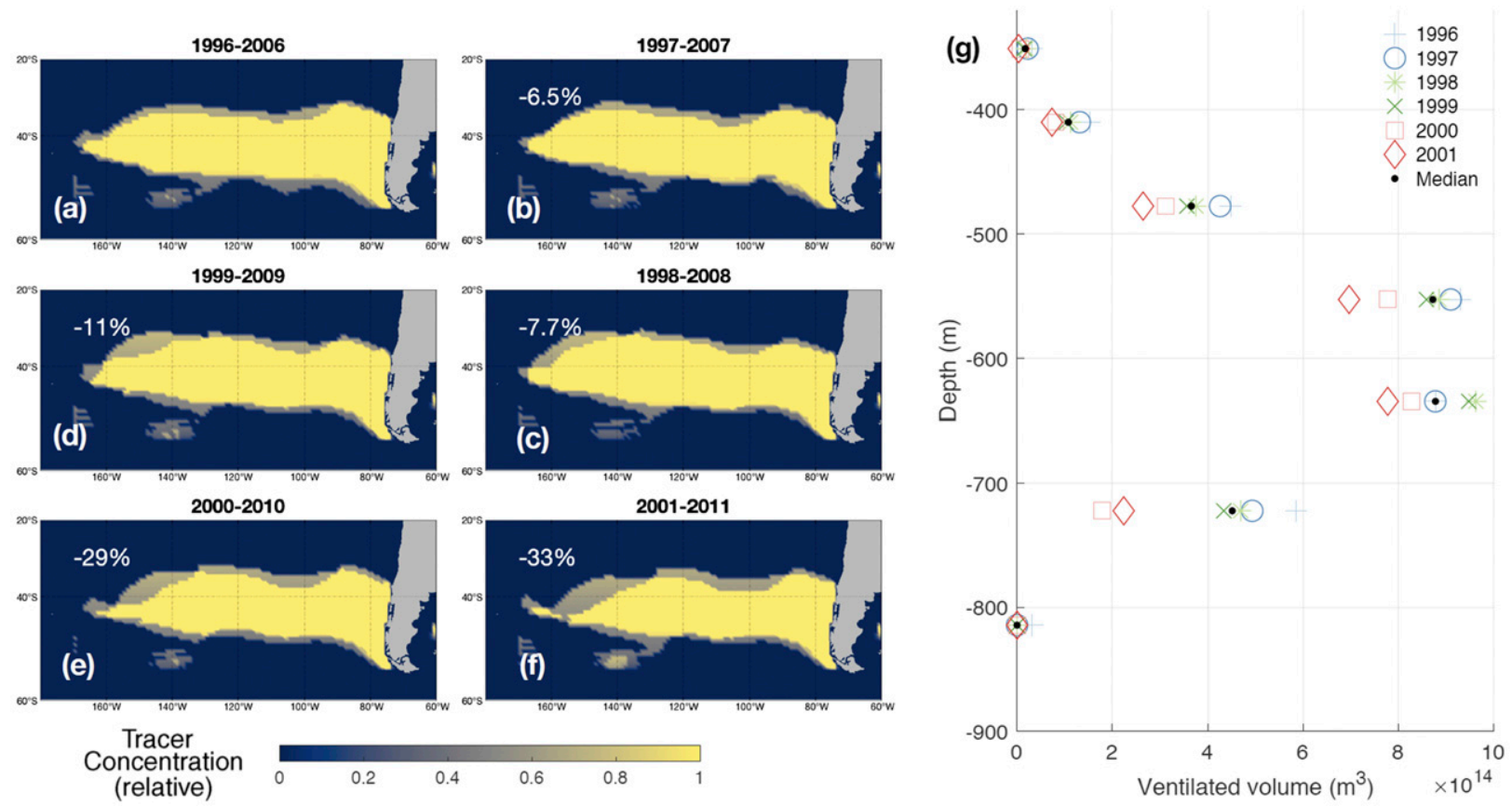

FIG. 4. (a)-(f) Interannual variability in the RVP expressed as column-integrated volume in units of $10^{12} \mathrm{~m}^{3}$. The years listed in the titles indicate the dates of the tracer transport (i.e., released 1 Jan 1996 and transported until 31 Dec 2006). Percentages in the top left of each panel indicate volume changes relative to the 1996-2006 experiment. (g) Comparison of ventilated volume by depth level across release years. We used these tracer distributions to define the RVP in a self-consistent way; in this work, we do not examine the causes for the variation in RVP.

$$
\left(\frac{\partial J}{\partial T}\right)_{S}=\left(\frac{\partial J}{\partial \rho}\right)_{T}\left(\frac{\partial \rho}{\partial T}\right)_{S}+\left(\frac{\partial J}{\partial T}\right)_{\rho}
$$

The first term on the right-hand side of Eq. (2) is the "dynamic" component of the sensitivity (i.e., sensitivity to changes in density), and the second term on the right-hand side is the "kinematic" component (i.e., dynamically inactive sensitivities to temperature anomalies). Using the coefficient of thermal expansion $\alpha$ and coefficient of haline contraction $\beta$, defined as

$$
\alpha \equiv-\frac{1}{\rho}\left(\frac{\partial \rho}{\partial T}\right)_{S} \text { and } \beta \equiv \frac{1}{\rho}\left(\frac{\partial \rho}{\partial S}\right)_{T},
$$

we can write

$$
\left(\frac{\partial J}{\partial S}\right)_{T}=\left(\frac{\partial J}{\partial \rho}\right)_{T}\left(\frac{\partial \rho}{\partial S}\right)_{T}=\beta \rho\left(\frac{\partial J}{\partial \rho}\right)_{T},
$$

and the dynamic sensitivity becomes

$F_{\mathrm{dyn}}=\left(\frac{\partial J}{\partial \rho}\right)_{T}\left(\frac{\partial \rho}{\partial T}\right)_{S}=\frac{1}{\beta \rho}\left(\frac{\partial J}{\partial S}\right)_{T}\left(\frac{\partial \rho}{\partial T}\right)_{S}=-\frac{\alpha}{\beta}\left(\frac{\partial J}{\partial S}\right)_{T}$.

We can write the kinematic sensitivity as

$$
F_{\text {kin }}=\left(\frac{\partial J}{\partial T}\right)_{S}+\frac{\alpha}{\beta}\left(\frac{\partial J}{\partial S}\right)_{T} .
$$

Physically, kinematic sensitivities indicate the linear response of the objective function to the simultaneous application of a small temperature change and a compensating salinity change of the form $\Delta S=\Delta T \alpha / \beta$, such that density remains constant following the linearized equation of state for seawater, $\rho=\rho_{0}(1-\alpha \Delta T+\beta \Delta S)$. We can refer to these perturbations as "densitycompensated temperature anomalies." In contrast, dynamic sensitivities indicate the linear response of the objective function to the application of a temperature change $\Delta T$ or a density-equivalent salinity change of $\Delta S=-\Delta T \alpha / \beta$ in the equation of state. The linear response is given by $\Delta J=F_{\mathrm{dyn}} \Delta T=F_{\mathrm{dyn}}(-\Delta S \beta / \alpha)$. We use 14-day averaged, three-dimensional $\alpha / \beta$ fields derived from ECCOv4-r2 potential temperatures and salinities using the TEOS-10 toolbox (McDougall and Barker 2011). Next, we examine the kinematic and dynamic sensitivities of RVPh.

In this paper, we follow the naming and conceptual conventions established in the adjoint modeling literature, specifically the use of kinematic and dynamic sensitivities (e.g., Marotzke et al. 1999a; Jones et al. 2018). Kinematic sensitivities are conceptually similar to 


\section{$95 \mathrm{~m}$}
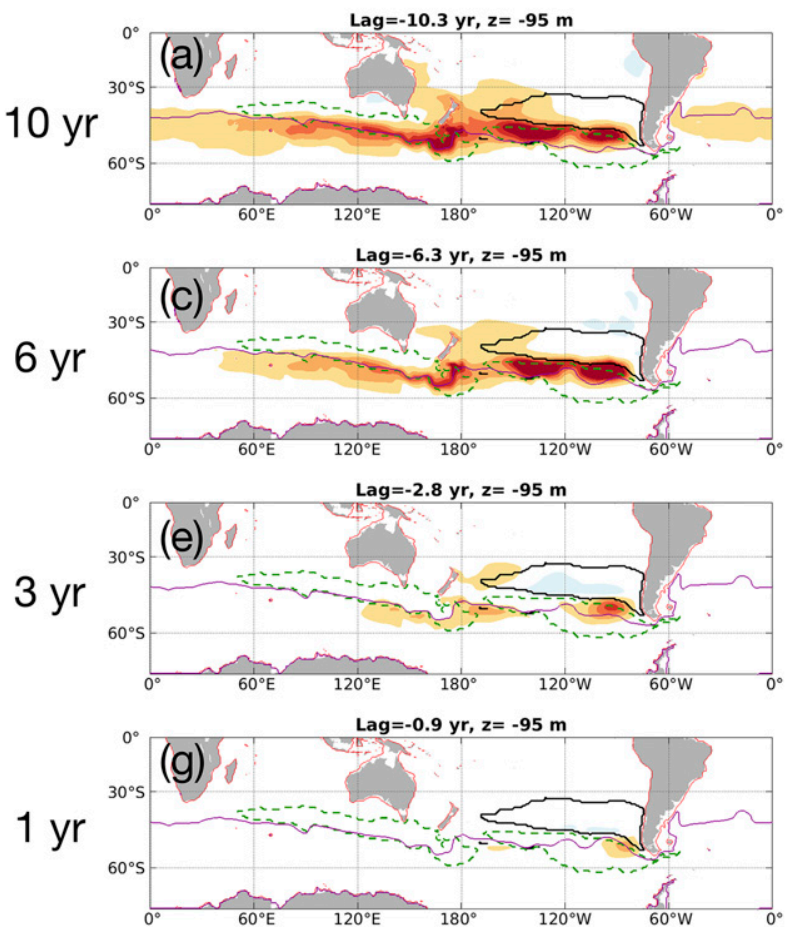

$553 \mathrm{~m}$
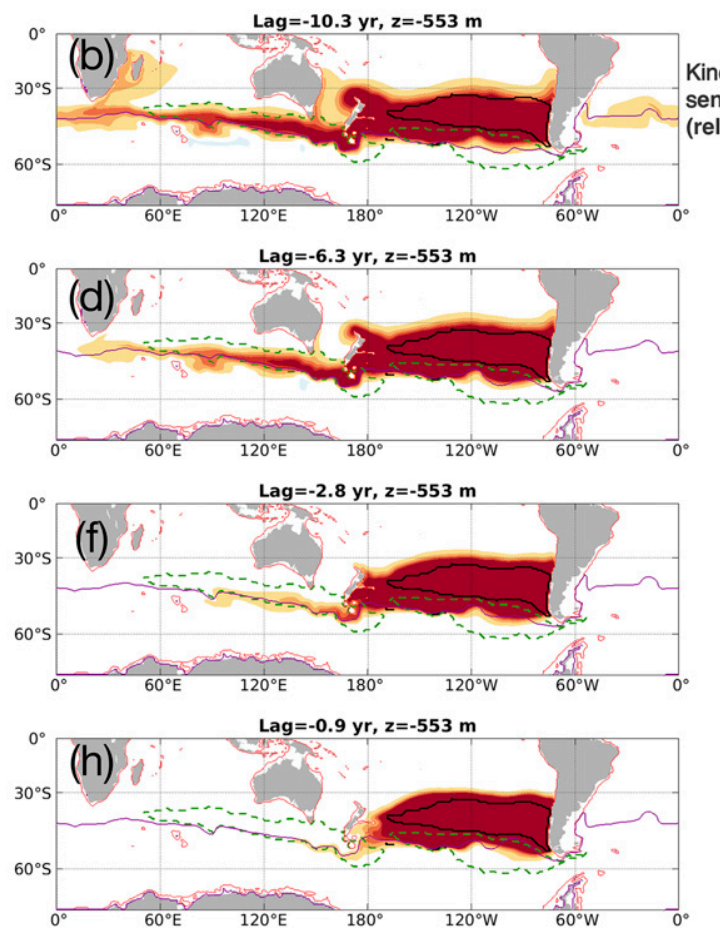

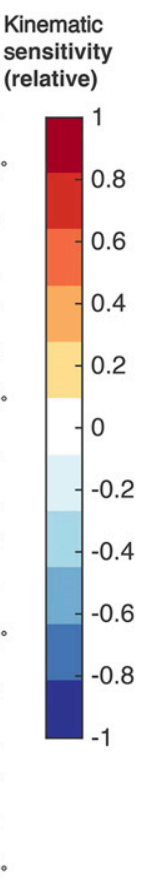

FIG. 5. Relative ensemble mean sensitivities of RVPh to density-compensated temperature anomalies (i.e., kinematic sensitivities). Also shown is a section through the RVP at roughly 553-m depth (black solid line), a section through the mixed layer mask at roughly 300-m depth (green dashed line), a depth contour (red solid line; $95 \mathrm{~m}$ for the left column, $552 \mathrm{~m}$ for the right column), and the SAF proxy (magenta solid line). All fields have been scaled by the gridcell thickness $\Delta z$ to allow for comparison between different depth levels. The plots have been further scaled by the global maximum sensitivity for the entire adjoint run to allow for comparison between different lags.

sensitivities to "spice" anomalies (Flament 2002), and dynamic sensitivities are conceptually similar to sensitivities to "heave" anomalies (Bindoff and McDougall 1994). However, despite their resemblance, it would be misleading to conflate kinematic sensitivities with sensitivities to spice anomalies, and it would be misleading to conflate dynamic sensitivities with sensitivities to heave anomalies. Their derivations and resulting definitions are not rigorously identical. In addition, there is a difference in how these quantities are normally used; spice and heave are typically used to decompose local potential temperature anomalies into these two components, whereas kinematic and dynamic adjoint sensitivities are more generally used to show impacts on an objective function over different spatial and temporal lags.

At present, adjoint sensitivity fields in ECCOv4 do not include sensitivity to changes in mixing as parameterized by the GGL mixed layer turbulence closure scheme. Also, the sensitivity fields do not include the sensitivity to changes in sea ice. The adjoint sensitivity calculations essentially treat GGL mixing and sea ice as fixed processes. We apply a mask of the form $1-f$, where $f$ is the local sea ice concentration, to all surface sensitivity fields to account for the lack of sensitivity to sea ice change.

\section{b. Sensitivity to changes at constant density}

Kinematic sensitivity fields approximately indicate potential source water pathways. More specifically, one can think of the kinematic sensitivity fields as indicating the eventual response of annual mean RVP heat content to a spatially uniform, density-compensated potential temperature perturbation that is sustained for some time (in our case, 2 weeks) and allowed to propagate. Regions with zero sensitivity cannot affect RVPh; such regions are not connected to the RVP via advection and mixing on the associated time scales. The kinematic sensitivity fields are positive or zero nearly everywhere; an increase (decrease) in temperature in regions with nonzero sensitivities eventually increases (decreases) RVP heat content on the indicated lag time scale (Fig. 5).

The near-surface kinematic sensitivity fields highlight the potential propagation pathways of anomalies into 
the SAMW formation regions, where they can be subducted below the mixed layer and exported into the thermocline (Fig. 5, left column, and Animation S2). In the Pacific basin, the largest near-surface sensitivity fields tend to be found just north of the SAF proxy, within or upstream of regions of deep mixed layers and mostly south of the RVP areal extent. In the Indian basin, the largest near-surface sensitivity fields are found along the SAF proxy or just south of it. The fields cross over the SAF around Campbell Plateau and South Australian basin, suggesting cross-front exchange in this region.

Density-compensated anomalies cannot typically propagate from directly above the RVP into the RVP itself on the time scales considered here; they are not typically advected into the regions of deep mixing. On time scales longer than 10 years, the near-surface sensitivities extend across the entire Southern Ocean, putting a lower bound on the temperature anomaly propagation time scale from the Atlantic to the RVP (Fig. 5, left column). On time scales longer than roughly 5-6 years, we find sensitivities south of the SAF proxy in the Indian basin; here, wind stress may advect anomalies across the SAF via Ekman transport. On shorter time scales, the sensitivity fields are more localized around the southeast Pacific mixed layer region and are typically smaller in magnitude relative to the deeper levels. Temperature anomalies can only affect $\mathrm{RVPh}$ if they have sufficient time to propagate into the mixed layer, subduct, and get exported; only very local, targeted anomalies can affect RVPh on time scales shorter than 1-2 years. The persistent local maximum in the southeast Pacific indicates a relatively rapid route from the surface into the RVP, which is consistent with a welldocumented subduction and export pathway in that location (Sallée et al. 2010).

The subsurface sensitivity fields highlight the long residence time of local hypothetical perturbations in the subsurface of the gyre, as well as the pathways of subsurface ocean advection into the RVP (Fig. 5, right column, and Animation S3). On time scales longer than 10 years, we find sensitivities extending along the East Australian Current and, in contrast with the surface sensitivities, sensitivities along the Agulhas Current and associated retroflection as well. Surface anomalies in the Agulhas Current cannot affect RVPh on the time scales considered here, but anomalies in the subsurface (here, roughly $550 \mathrm{~m}$ ) can eventually alter $\mathrm{RVPh}$. We also find some sensitivity at this depth extending along the Brazil Current. Notably, the Agulhas Current is the only major Southern Hemispheric western boundary current with zero kinematic sensitivity in the near surface.

The global mean RMS kinematic sensitivity decreases with time scale (Fig. 6a). It is reasonably well described
$\left(R^{2}>0.99\right)$ by an exponential function with a decay rate of about 10 years. The decay partly reflects the fact that as we consider longer time scales, RVPh becomes sensitive to a larger fraction of the ocean, so the global RMS sensitivity decreases. The decay also partly reflects the tendency of air-sea exchange, represented in ECCOv4 as bulk formulae with a prescribed set of atmospheric variables, to dampen potential temperature anomalies at the surface and thereby reducing the sensitivities. The linear change in sensitivity between lag 0 and lag 1 year reflects the 1-yr integration period over which the objective function is calculated. There is no sensitivity to anomalies after year 1, after the integration has finished. The ensemble standard deviation is small, indicating a relatively low level of interannual variability in sensitivity across our six-member ensemble.

We find nonzero sensitivities to hypothetical anomalies within the local RVP throughout the entire 16-yr adjoint sensitivity experiment, indicating that $\mathrm{RVPh}$ is sensitive to local density-compensated temperature anomalies on time scales of at least 16 years (Fig. 6b) The ensemble mean RMS local sensitivity time series is well-described $\left(R^{2}>0.99\right)$ by a two-term exponential with decay rates of 4.4 and 10.9 years. The nonlocal RMS sensitivities outside of the RVP exceed the local sensitivities on time scales longer than roughly 5 years (Fig. 6b). RMS sensitivities outside of the MLD mask are larger than those within the MLD mask on time scales shorter than about 8 years (Fig. 6c). This is largely due to the fact that sensitivities exist below the surface, for example, in the RVP itself, where the overlying mixed layers are typically shallow.

Outside of the RVP, we mostly find nonzero sensitivities just north of the SAF proxy in all three ocean basins, in what may be considered the northern extent of the ACC (Fig. 6d). The near-surface sensitivity fields display a clear seasonal cycle, with the RMS mean peaking in August in the Pacific and Indian basins, during the strong mixing phase that occurs as the mixed layer deepens before reaching its maximum depth in mid-September (Fig. 6e). The sensitivity fields spread westward with lead time, reflecting the advective time scale between basins (Figs. 6e,f). The RMS sensitivity in the west Pacific exceeds the east Pacific value on time scales longer than roughly 4.4 years.

\section{c. Sensitivity to changes in density}

The dynamic sensitivity fields indicate patterns of density change that can alter RVPh, potentially by inducing changes in isopycnal tilt and thereby altering the associated transport and heat convergence into the RVP. More specifically, one can think of the dynamic sensitivity fields as indicating the eventual response 
(a)

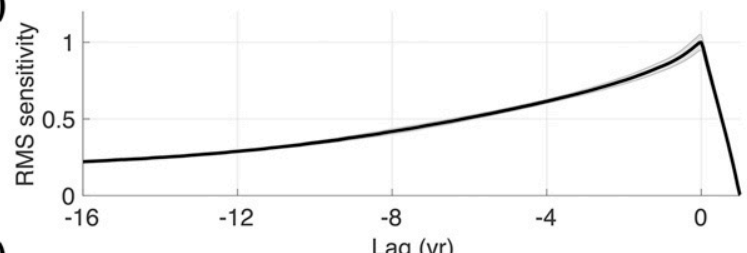

(c)

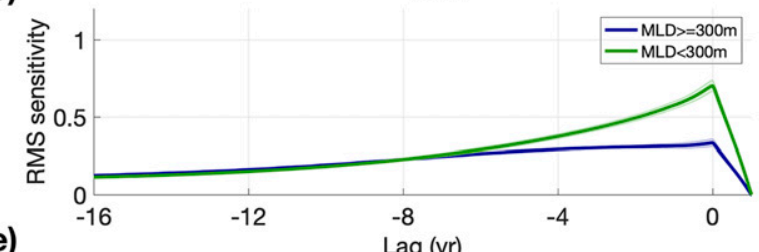

(e)

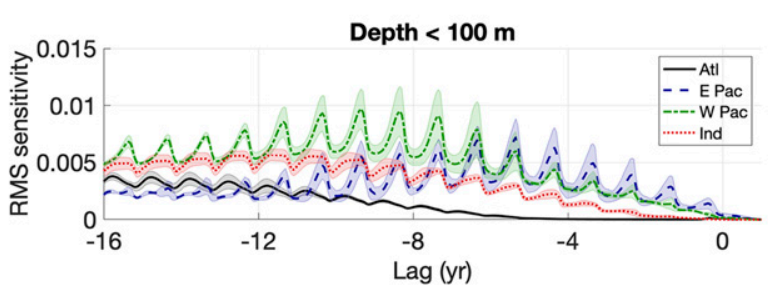

(b)

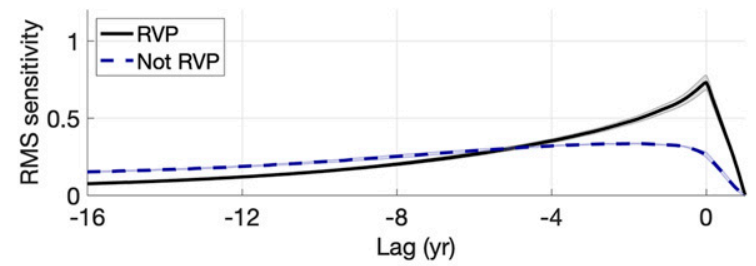

(d)

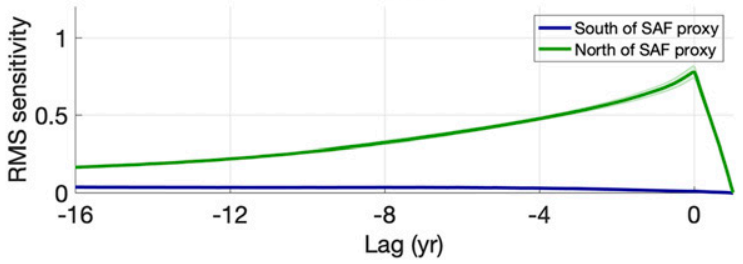

(f)

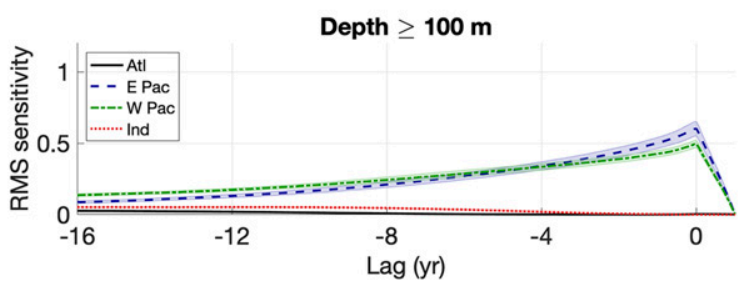

FIG. 6. Kinematic RMS sensitivities averaged over different volumes, indicating propagation time scales and relative magnitudes. The time scale increases from right to left, as indicated by more negative lags (i.e., longer lead times). Lines indicate ensemble means, and shading indicates one standard deviation across the ensemble. All values have been scaled by the same maximum of $0.0017^{\circ} \mathrm{C}^{\circ} \mathrm{C}^{-1}$ and can be compared relative to each other. We show (a) the global mean sensitivity, (b) within the control volume (RVP) or not, (c) inside or outside of the 300-m MLD mask, (d) north or south of the SAF proxy, (e) in the upper $100 \mathrm{~m}$ in different basins, and (e) below $100 \mathrm{~m}$ in different basins. Note that the axes in (e) differ from the others. To define the basins, we used the standard ECCOv4 masks that are part of the gcmfaces package (see acknowledgments), and we chose $120^{\circ} \mathrm{W}$ as the dividing longitude between the east and west Pacific basins. South of $30^{\circ} \mathrm{S}$, the basins are roughly demarcated by longitude: Atlantic $\left(70^{\circ} \mathrm{W}-20^{\circ} \mathrm{E}\right)$, Indian $\left(20^{\circ}-150^{\circ} \mathrm{E}\right)$, western Pacific $\left(150^{\circ} \mathrm{E}-120^{\circ} \mathrm{W}\right)$, and eastern Pacific $\left(120^{\circ}-70^{\circ} \mathrm{W}\right)$.

of annual mean RVP heat content to a spatially uniform potential temperature perturbation, or a densityequivalent salinity perturbation, that is sustained for some time ( 2 weeks, as with the kinematic sensitivity case) and allowed to affect the oceanic density structure. Regions of zero sensitivity cannot affect $\mathrm{RVPh}$; such regions are not dynamically connected to the RVP. The dynamic sensitivity fields are both positive and negative, with the dipoles highlighting regions where a change in isopycnal tilt will change the associated circulation and ultimately RVPh (Fig. 7).

The near-surface dynamic sensitivity fields are mostly negative across all lags, with local exceptions south of Australia and in the eastern tropical Pacific (Fig. 7, left column). Negative values indicate regions where a hypothetical temperature increase, which will decrease density, will ultimately decrease RVP heat content. Similarly, in these regions a hypothetical temperature decrease, which will increase density, will ultimately increase RVP heat content. It is important to note that, due to technical limitations, our adjoint sensitivity fields do not represent nonlinear changes. They do reflect changes in circulation and diffusion. So the negative near-surface values may represent the fact that, even under fixed mixing conditions, relatively lighter water may not reach the depths of the RVP as readily as relatively denser water, where "relative" refers to the background ECCOv4 state around which the adjoint sensitivities are calculated. Alternatively, the negative near-surface values may represent a hypothetical decrease in RVP heat convergence induced by a surface decrease in density, or the values may represent a hypothetical increase in RVP heat convergence induced by a surface increase in density. As with the kinematic sensitivity fields, on shorter time scales the dynamic sensitivities become increasingly localized to the southeastern edge of the RVP, near the southern tip of South America.

In contrast with the near-surface kinematic sensitivity fields, the near-surface dynamic sensitivity fields feature a persistent negative local minimum along the western coast of South America (Fig. 7, left column, and Animation S4). Considered together with the small positive values in the eastern tropical Pacific, this dipole reflects a sensitivity to the across-shelf pressure gradient. Variations in the across-shelf pressure gradients are associated with changes in basin-scale pressure gradients and the 


\section{$95 \mathrm{~m}$}
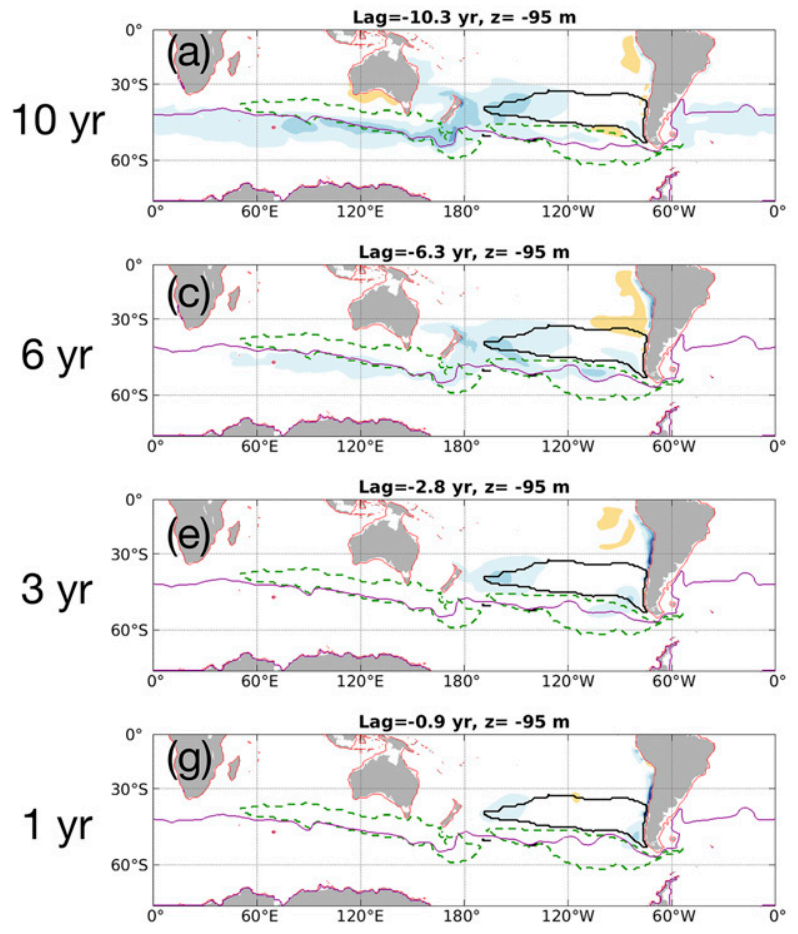

\section{$553 \mathrm{~m}$}

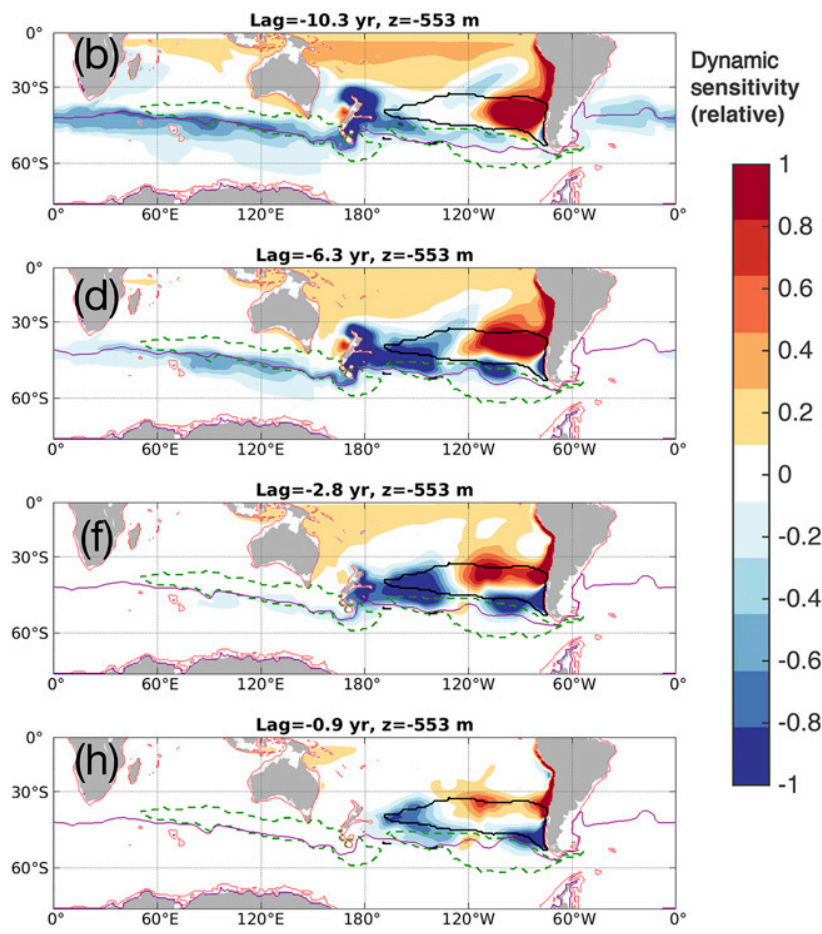

FIG. 7. Relative ensemble mean sensitivities to changes in density (i.e., dynamic sensitivities). Scaling and units are the same as in Fig. 5.

associated basin-scale circulation, which can ultimately change heat convergence and thus heat content within a selected ocean volume (Fukumori et al. 2015; Jones et al. 2018; Hughes et al. 2018).

The subsurface dynamic sensitivity fields highlight the sensitivity of annual mean RVP heat content to basinwide density contrasts, equivalently expressed as tilted basin-scale isopycnal surfaces (Fig. 7, right column, and Animation S5). This basin-scale structure is associated with the circulation of the SPG, which is in part maintained by pressure gradients induced by wind stress curl. We find a persistent sensitivity dipole stretched across the RVP, with positive values to the east and negative values to the west. The positive values reach into the tropics and extend westward with time scale, across both the Pacific and Indian basins. To illustrate the structure of these fields, consider a hypothetical potential temperature anomaly characterized by warming to the east of the RVP and cooling to the west of the RVP, imposed on the model vertical level centered at $553 \mathrm{~m}$ (Fig. 7d). The warming to the east would decrease density at $553 \mathrm{~m}$ and, based on the positive sign of the sensitivity field, ultimately contribute to an increase $\mathrm{RVPh}$. The cooling to the west would increase density at $553 \mathrm{~m}$ and, based on the negative sign of the sensitivity field, it would also increase RVPh. The change in RVPh induced by any anomaly is the product of the sensitivity field and the imposed anomaly, that is, $\Delta J=F_{\mathrm{dyn}} \Delta T$. In this scenario, we have imposed isopycnal deepening to the east and isopycnal shoaling to the west. In the RVP, isopycnal surfaces at roughly $500-600 \mathrm{~m}$ tend to shoal from west to east, so our imposed perturbation alters isopycnal surfaces locally, ultimately changing transport and increasing heat convergence in the RVP (Jones et al. 2018).

The subsurface sensitivity fields also feature a persistent sensitivity along the western coast of South America (Fig. 7, right column). In contrast to the near-surface fields, which are fairly consistently negative along the shelf, the along-shelf subsurface fields are positive to the north and negative to the south. The north-south sign contrast indicates a sensitivity to barotropic structure, whereas the surface-subsurface sign contrast highlights an overall sensitivity to baroclinic density structure above the continental shelf. In addition, the subsurface fields display characteristic fingerprints of baroclinic Rossby waves, as seen by westward propagating positive anomalies at depth (Animation S5). As with the surface fields, on shorter time scales the subsurface dynamic sensitivities become increasingly localized, albeit with a different structure than the surface fields. The subsurface fields are localized around the edge of the RVP, indicating a sensitivity to density contrasts across the RVP that can alter fluxes across the boundary of the RVP, and the subsurface sensitivities are also localized 
(a)

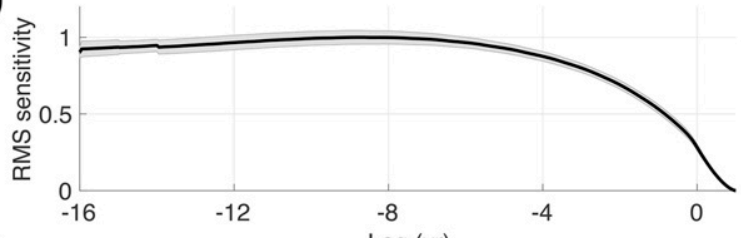

(c)

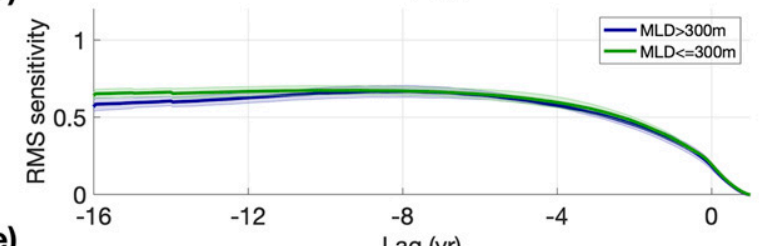

(e)

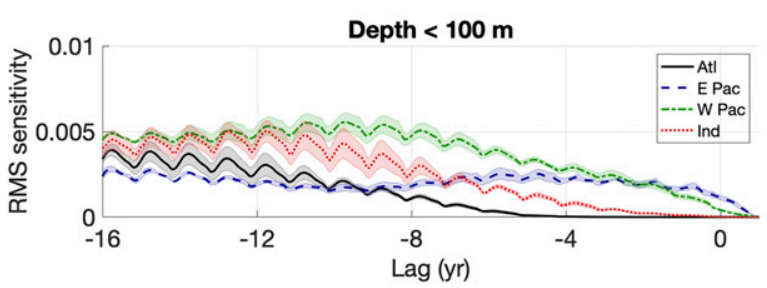

(b)

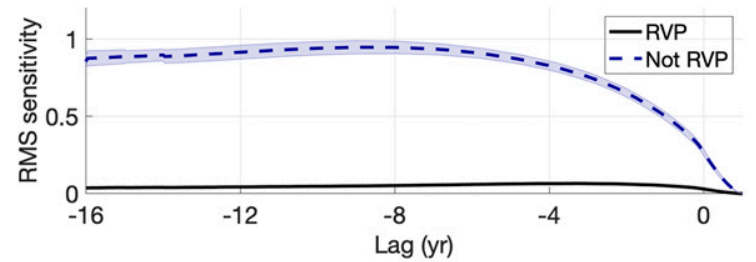

(d)

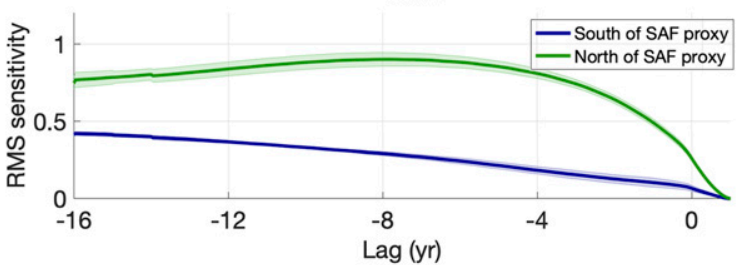

(f)

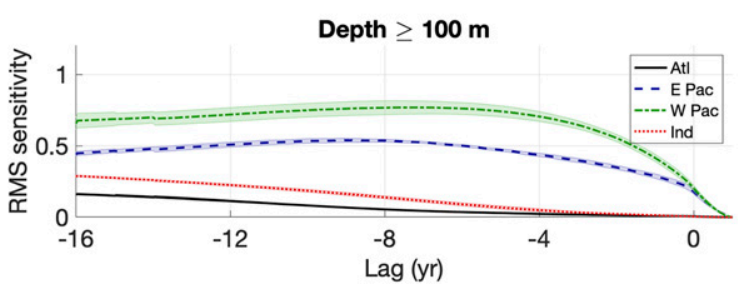

FIG. 8. RMS dynamic sensitivity time series. The panels and scaling are identical to those in Fig. 6 . The time scale increases from right to left.

along the western coast of South America, indicating a short-timescale sensitivity to density changes along the continental shelf.

The globally averaged RMS dynamic sensitivity increases with time scale, reaching a maximum at roughly 8.7 years (Fig. 8a). Much of this sensitivity comes from outside the RVP, particularly near its boundary (Fig. 8b). RMS sensitivity is similar inside and outside of the MLD mask, indicating that when considering $\mathrm{RVPh}$, we need to study dynamic changes both inside and far outside of the regions of deep mixing (Fig. 8c). The RMS sensitivity is persistently larger north of the SAF proxy, although much of this is located just north of the SAF, and the RMS sensitivity south of the SAF increases roughly linearly with time scale (Fig. 8d). The near-surface fields also display a seasonal cycle, with similar timings as the kinematic fields (Fig. 8e). Notably, the RMS dynamic sensitivity is persistently higher in the west Pacific than in the east Pacific, indicating the importance of dynamic basin-scale changes (Fig. 8h). The RMS sensitivity in the Indian and Atlantic basins increases with time scale, although the values are negligibly small (less than $3 \%$ of the maximum) for short time scales (about 2.5 years for the Indian basin and 5 years for the Atlantic basin).

\section{Discussion}

In the canonical view of Southern Ocean meridional overturning circulation (MOC), Circumpolar Deep
Water upwells south of the ACC, where it is brought to the surface and exported northward; this water is modified by air-sea fluxes and is ultimately subducted as SAMW and AAIW (Marshall and Speer 2012). As a result of this overturning circulation, the properties of SAMW and AAIW are potentially sensitive to anomalies in near-Antarctic waters. For example, the variability of the Amundsen Sea low (ASL) can affect the interannual and interdecadal variability of SAMW in the Southeast Pacific via cross-frontal Ekman transport of Antarctic surface waters (Naveira Garabato et al. 2009; Close et al. 2013). In 2008-10, a deep ASL enhanced the meridional wind-driven sea ice export from the eastern Ross Sea; the sea ice melt introduced a cold surface freshwater anomaly that was advected across the PF and SAF by Ekman transport and then transported into the SAMW formation region by the ACC (Cerovečki et al. 2019). In this context, our adjoint sensitivity results may appear surprising, in that they show relatively weak sensitivities to anomalies in the Ross Sea. Our results are not inconsistent with those studies, but there are several factors to consider when comparing our results with those obtained using other approaches, as discussed below.

\section{a. RVPh is a fixed-volume quantity}

Our control volume is fixed relative to the model grid. Although RVP captures the mean position of the ventilated water, it does not move with isopycnal heave. 
Because it overlaps with both SAMW and AAIW, it is more general than either water mass, but we must be careful not to conflate SAMW/AAIW with the RVP. Isopycnal heave in the subtropical gyre can affect $\mathrm{RVPh}$ without necessarily changing the heat content of the recently subducted SAMW. However, RVPh can still tell us something about subduction. The majority of recent heat uptake by SAMW is driven by a thickening of the associated isopycnal layers, driven by changes in wind forcing and subduction in the deep mixed layer region Gao et al. (2018). Considering SAMW in the Pacific basin, its local mean temperature is correlated with remote forcing (e.g., air-sea heat flux, wind stress) with a lag that is attributed to transport, whereas its total heat content is controlled largely by layer thickness, which is driven by local wintertime forcing (Meijers et al. 2019). These results are consistent with the our adjoint sensitivity fields, which largely capture mechanisms that can affect mean temperature within the SAMW as opposed to those that can affect total heat content via changing layer thickness. It would be useful to examine the sensitivities in an adjoint model that uses isopycnal surfaces as its vertical coordinate, but this is beyond the scope of this paper.

\section{b. Zonal flow dominates meridional overturning}

The largely zonal volume transport of the ACC is at least an order of magnitude larger than the volume transport associated with the MOC (Talley 2013; Donohue et al. 2016). As such, we might expect our adjoint sensitivity fields to reflect the dominance of ACC transport in the southeast Pacific. According to these fields, sensitivity to high-latitude processes is small but nonzero. To examine the impacts of actual temperature and salinity anomalies on RVPh, one could examine the combination of sensitivity fields together with temperature and/or salinity anomaly fields. In this work, we focus on the sensitivity fields themselves, as these could potentially be combined with a large variety of anomaly fields in order to address different questions (e.g., how does the SAM forcing pattern affect RVPh across different time scales?)

\section{c. Cross-front exchange rates differ between data products}

Cross-front exchange in the SO is highly localized, occurring in relatively narrow longitude bands in the lee of bathymetric features (Thompson and Sallée 2012). The propagation of anomalies from the Ross Gyre to the subtropics occurs largely via two distinct exchange windows in the southeast Pacific and the central Pacific; on time scales of roughly 1-3 years, the central Pacific pathway enables transport from
Antarctic surface waters to the deep mixed layer region (Cerovečki et al. 2019). The subsurface exchange pathway in the central Pacific (around the Eltanin fracture zone, between roughly $110^{\circ}$ and $160^{\circ} \mathrm{W}$ ) is driven by enhanced diapycnal mixing near the relatively rough topography and temporal circulation variability on time scales longer than 90 days (McAufield 2019). Because of its relatively coarse resolution, it is possible that ECCOv4-r2 may have a lower cross-frontal exchange rate than that of higher-resolution data products, but a lack of observational data constraints makes it challenging to discriminate among estimates. A thorough, quantitative comparison of exchange rates between ECCOv4-r2 and other data products would be a useful addition to this work.

\section{d. Mixed layer depth}

In this work, we calculate mixed layer depth using a criteria based on the density change associated with a temperature variation of $\Delta T=0.8^{\circ} \mathrm{C}$ (Kara et al. 2000). Compared with other methods, this threshold approach tends to be biased toward deeper values (Forget et al 2015c, supporting information). Because we discard all tracer above the maximum mixed layer, this implies that our estimate of the subducted volume may be somewhat conservative. It is possible that our results would be different using another mixed layer scheme. That being said, the stratification and mixed layer properties in ECCOv4 compare well spatially with in situ profiles (Forget et al. 2015c, Fig. 6).

\section{e. Adjoint sensitivities use fixed vertical mixing and sea ice}

At present, adjoint sensitivity fields in ECCOv4 do not include sensitivities to changes in mixing as parameterized by the GGL mixed layer turbulence closure scheme. Also, the sensitivity fields do not include the sensitivity to changes in sea ice. Although the forward and adjoint runs do feature dynamic sea ice and vertical mixing as parameterized by GLL, the adjoint sensitivity calculations essentially treat them as fixed processes. Any processes that affect $\mathrm{RVPh}$ primarily through changing sea ice concentration and/or vertical mixing will not be represented in our sensitivity fields.

\section{Summary and conclusions}

We used numerical passive tracer experiments and physical state variables (i.e., mixed layer depth, potential density, potential vorticity) in an observationally constrained state estimate to identify the recently ventilated eastern Pacific sector of the Southern Ocean (RVP), which is a relatively efficient export pathway 


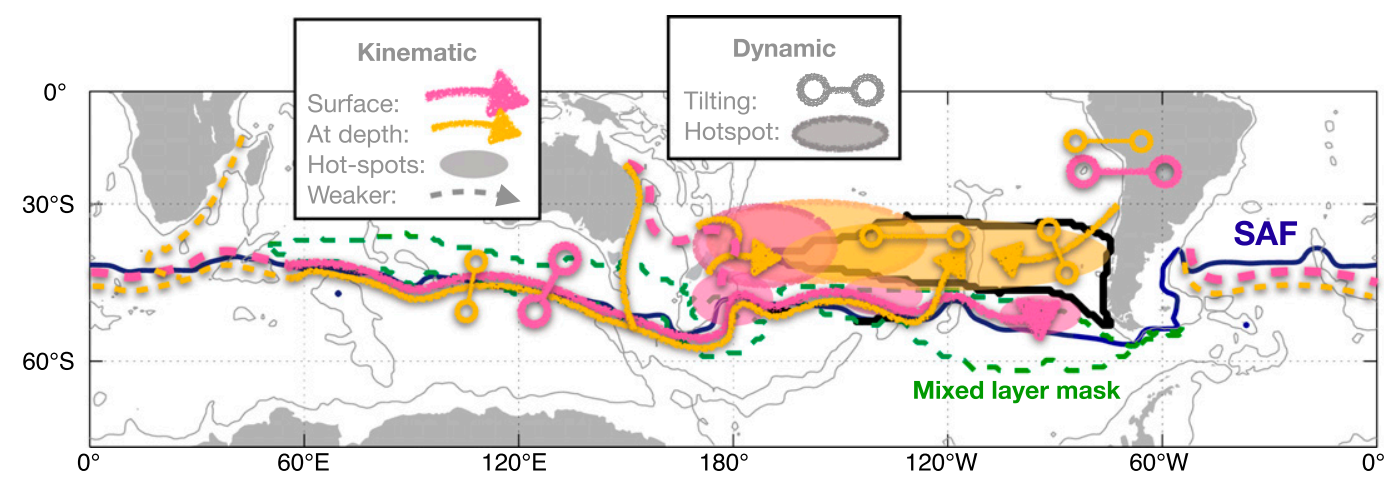

FIG. 9. Schematic illustrating the main kinematic and dynamic sensitivities up to $\sim 10$-yr lag. Chalk lines with arrows indicate kinematic sensitivities, with the vertical structure indicated by color. Weaker pathways are indicated by dashed lines. The circles connected by lines indicate where dynamic sensitivities resemble dipoles. Hotspots are defined as regions that are either perennially sensitive or regions that feature a large seasonal amplitude throughout the 10-yr time scale of the schematic. The reference contours include the RVP at $553 \mathrm{~m}$ (thick solid black line), the mixed layer mask at roughly 300-m depth (green dashed line), the SAF proxy (magenta solid line), and the 3000-m depth contour (thin gray lines).

from the surface ocean into the subsurface thermocline. The RVP, defined on a 10 -yr time scale, is located north of the -0.25 -m sea surface height contour (i.e., the SAF proxy) and north of the deep mixed layer regions, highlighting the ventilation pathway from the tip of South America, along the eastern Pacific boundary and out across the South Pacific Gyre (SPG) in the subsurface. The RVP varies with depth, reaching maximum areal extent between 500 and $600 \mathrm{~m}$, and it features some variation with tracer release year, mostly in its western extent. The overall spatial pattern of the subducted tracer is consistent with estimates from an eddy-permitting model (Jones et al. 2016).

We used the adjoint capabilities of MITgcm to calculate the sensitivities of annual mean heat content within the fixed volume RVP (i.e., RVPh) to anomalies in potential temperature and salinity. These sensitivities are four-dimensional (i.e., latitude, longitude, depth, and time) and indicate the anomaly patterns that can have the largest potential impact on RVPh after the appropriate lag time has elapsed (Fig. 9). In terms of sensitivities to surface anomalies, RVPh is most sensitive to anomalies along the SAF proxy, upstream of the subduction hotspot in the southeast Pacific. The sensitivity signal crosses the SAF proxy around Campbell Plateau and just south of Australia, indicating possible wind-driven cross-frontal exchange in that region. This result is consistent with estimates of the spatial pattern of meridional Ekman transport of atmospheric carbon in an eddy-permitting state estimate (Ito et al. 2010). In terms of sensitivities to subsurface anomalies, RVPh is most sensitive to basin-scale changes in density, as indicated by the persistent dipole in subsurface dynamic sensitivity (Fig. 7). The sensitivity dipole is centered around the same latitudes as the RVP, extending upstream along the ACC and northward into the tropical Pacific with increasing time scale. This persistent dipole implies that property gradients between the SPG and the ACC are important for interannual variability in $\mathrm{RVPh}$.

By the end of the twenty-first century, Southern Ocean wind stress is expected to strengthen in magnitude and move poleward, resulting in a poleward shift of the gyres, and mixed layers are expected to shoal (Meijers 2014). Our results suggest that the resulting subtropical, basin-scale temperature and salinity changes induced by the expected shifts in wind stress and heat flux can have a considerable impact on the heat distribution of the ventilated southeast Pacific, across the density ranges of the base of the SAMW, AAIW, and the lightest CDW. In a companion manuscript, we examine the sensitivities of RVP heat content to changes in surface forcing (Jones et al. 2019).

Acknowledgments. This study is supported by grants from the Natural Environment Research Council (NERC), including 1) The North Atlantic Climate System Integrated Study (ACSIS) (Grant NE/N018028/1, authors DJ, ES), 2) Securing Multidisciplinary UndeRstanding and Prediction of Hiatus and Surge events (SMURPHS) (Grant NE/N006038/1, author EB), and 3) Ocean Regulation of Climate by Heat and Carbon Sequestration and Transports (ORCHESTRA) (Grant NE/N018095/1, authors EB, AM, SJ). GF is supported by NASA Award 6937342 and Simons Foundation Award 549931. Numerical model runs were carried out on ARCHER, the U.K. national HPC facility (http://archer.ac.uk/). 
Adjoint code was generated using the TAF software tool, created and maintained by FastOpt GmbH (http:// www.fastopt.com/). We used the gcmfaces package for plotting and analysis (https://github.com/gaelforget/ gcmfaces). The authors wish to thank two anonymous reviewers whose comments greatly improved the quality of this paper.

Data availability statement: The model used here is an instance of the ECCOv4-r2 state estimate (https:// github.com/gaelforget/ECCOv4) as an instance of the MIT General Circulation Model (MITgcm; http:// mitgcm.org/). Specific model configuration files, input data, and sample output available via Zenodo (Jones 2020).

\section{REFERENCES}

Armour, K. C., J. Marshall, J. R. Scott, A. Donohoe, and E. R. Newsom, 2016: Southern Ocean warming delayed by circumpolar upwelling and equatorward transport. Nat. Geosci., 9, 549-554, https://doi.org/10.1038/ngeo2731.

Bindoff, N. L., and T. J. McDougall, 1994: Diagnosing climate change and ocean ventilation using hydrographic data. J. Phys. Oceanogr., 24, 1137-1152, https://doi.org/10.1175/ 1520-0485(1994)024<1137:DCCAOV > 2.0.CO;2.

Cerovečki, I., and M. Mazloff, 2016: The spatiotemporal structure of diabatic processes governing the evolution of Subantarctic Mode Water in the Southern Ocean. J. Phys. Oceanogr., 46, 683-710, https://doi.org/10.1175/JPO-D-14-0243.1.

- L. D. Talley, M. R. Mazloff, and G. Maze, 2013: Subantarctic mode water formation, destruction, and export in the eddy-permitting Southern Ocean state estimate. J. Phys. Oceanogr., 43, 1485-1511, https://doi.org/10.1175/ JPO-D-12-0121.1.

, A. J. S. Meijers, M. R. Mazloff, S. T. Gille, V. M. Tamsitt, P. R. Holland, and V. M. Tamsitt, 2019: The effects of enhanced sea ice export from the Ross Sea on recent cooling and freshening of the Southeast Pacific. J. Climate, 32, 2013-2035, https://doi.org/10.1175/JCLI-D-18-0205.1.

Cessi, P., and P. Otheguy, 2003: Oceanic teleconnections: Remote response to decadal wind forcing. J. Phys. Oceanogr., 33, 1604-1617, https://doi.org/10.1175/2400.1.

Close, S. E., A. C. Naveira Garabato, E. L. McDonagh, B. A. King, M. Biuw, and L. Boehme, 2013: Control of mode and intermediate water mass properties in drake passage by the Amundsen Sea low. J. Climate, 26, 5102-5123, https://doi.org/ 10.1175/JCLI-D-12-00346.1.

Dee, D. P., and Coauthors, 2011: The ERA-Interim reanalysis: Configuration and performance of the data assimilation system. Quart. J. Roy. Meteor. Soc., 137, 553-597, https://doi.org/ 10.1002/qj.828.

Donohue, K. A., K. L. Tracey, D. R. Watts, M. P. Chidichimo, and T. K. Chereskin, 2016: Mean Antarctic circumpolar current transport measured in drake passage. Geophys. Res. Lett., $\mathbf{4 3}$, 11 760-11767, https://doi.org/10.1002/2016GL070319.

Downes, S. M., N. L. Bindoff, S. M. Downes, N. L. Bindoff, and S. R. Rintoul, 2009: Impacts of climate change on the subduction of mode and intermediate water masses in the Southern Ocean. J. Climate 22, 3289-3302, https://doi.org/ 10.1175/2008JCLI2653.1.
Durack, P. J., and S. E. Wijffels, 2010: Fifty-year trends in global ocean salinities and their relationship to broad-scale warming. J. Climate, 23, 4342-4362, https://doi.org/10.1175/2010JCLI3377.1.

Errico, R. M., 1997: What is an adjoint model? Bull. Amer. Meteor. Soc., 78, 2577-2591, https://doi.org/10.1175/1520-0477(1997) $078<2577$ :WIAAM $>2.0$.CO;2.

Fekete, B. M., C. J. Vörösmarty, and W. Grabs, 2002: Highresolution fields of global runoff combining observed river discharge and simulated water balances. Global Biogeochem. Cycles, 16, 1042, https://doi.org/10.1029/1999GB001254.

Flament, P., 2002: A state variable for characterizing water masses and their diffusive stability: Spiciness. Prog. Oceanogr., 54, 493-501, https://doi.org/10.1016/S0079-6611(02)00065-4.

Forget, G., J. M. Campin, P. Heimbach, C. N. Hill, R. M. Ponte, and C. Wunsch, 2015a: ECCO version 4: An integrated framework for non-linear inverse modeling and global ocean state estimation. Geosci. Model Dev., 8, 3071-3104, https://doi.org/ 10.5194/gmd-8-3071-2015.

— D. Ferreira, and X. Liang, 2015b: On the observability of turbulent transport rates by Argo: Supporting evidence from an inversion experiment. Ocean Sci. Discuss., 12, 1107-1143, https://doi.org/10.5194/osd-12-1107-2015.

,$- \ldots$, and,$- 2015 \mathrm{c}$ : On the observability of turbulent transport rates by Argo: Supporting evidence from an inversion experiment. Ocean Sci., 11, 839-853, https://doi.org/ 10.5194/os-11-839-2015.

Frölicher, T. L., J. L. Sarmiento, D. J. Paynter, J. P. Dunne, J. P. Krasting, and M. Winton, 2015: Dominance of the Southern Ocean in anthropogenic carbon and heat uptake in CMIP5 models. J. Climate, 28, 862-886, https://doi.org/10.1175/ JCLI-D-14-00117.1.

Fukumori, I., O. Wang, W. Llovel, I. Fenty, and G. Forget, 2015: A near-uniform fluctuation of ocean bottom pressure and sea level across the deep ocean basins of the Arctic Ocean and the Nordic Seas. Prog. Oceanogr., 134, 152-172, https://doi.org/ 10.1016/j.pocean.2015.01.013.

Gao, L., S. R. Rintoul, and W. Yu, 2018: Recent wind-driven change in Subantarctic Mode Water and its impact on ocean heat storage. Nat. Climate Change, 8, 58-63 https://doi.org/ 10.1038/s41558-017-0022-8

Gaspar, P., Y. Grégoris, and J. M. Lefevre, 1990: A simple eddy kinetic energy model for simulations of the oceanic vertical mixing: Tests at station Papa and long-term upper ocean study site.J. Geophys. Res., 95, 16179-16193, https://doi.org/ 10.1029/JC095iC09p16179.

Gent, P. R., and J. C. McWilliams, 1990: Isopycnal mixing in ocean circulation models. J. Phys. Oceanogr., 20, 150-155, https:// doi.org/10.1175/1520-0485(1990)020<0150:IMIOCM>2.0.CO;2.

Griewank, A., and A. Walther, 2012: Evaluating Derivatives: Principles and Techniques of Algorithmic Differentiation. 2nd ed. Society for Industrial and Applied Mathematics, $460 \mathrm{pp}$.

Hanawa, K., and L. Talley, 2001: Mode waters. Ocean Circulation and Climate, G. Siedler and J. Church, Eds., International Geophysics Series, Vol. 77, Academic Press, 373-386.

Heimbach, P., 2008: The MITgcm/ECCO Adjoint Modelling Infrastructure. CLIVAR Exchanges, Vol. 13, No.1, International CLIVAR Project Office, Southampton, United Kingdom, 14-17, https://eprints.soton.ac.uk/50120/1/Exch_44.pdf.

Helm, K. P., N. L. Bindoff, and J. A. Church, 2010: Changes in the global hydrological-cycle inferred from ocean salinity. Geophys. Res. Lett., 37, L18701, https://doi.org/10.1029/ 2010GL044222. 
Herraiz-Borreguero, L., and S. R. Rintoul, 2011: Subantarctic mode water: Distribution and circulation. Ocean Dyn., 61, 103-126, https://doi.org/10.1007/s10236-010-0352-9.

Hughes, C. W., J. Williams, A. Blaker, A. Coward, and V. Stepanov, 2018: A window on the deep ocean: The special value of ocean bottom pressure for monitoring the large-scale, deep-ocean circulation. Prog. Oceanogr., 161, 19-46, https://doi.org/10.1016/ j.pocean.2018.01.011.

Ito, T., M. Woloszyn, and M. Mazloff, 2010: Anthropogenic carbon dioxide transport in the Southern Ocean driven by Ekman flow. Nature, 463, 80-83, https://doi.org/10.1038/ nature 08687.

Iudicone, D., K. Rodgers, R. Schopp, and G. Madec, 2007: An exchange window for the injection of Antarctic intermediate water into the south Pacific. J. Phys. Oceanogr., 37, 31-49, https://doi.org/10.1175/JPO2985.1.

Johnson, G. C., and A. H. Orsi, 1997: Southwest Pacific Ocean water-mass changes between 1968/69 and 1990/91. J. Climate, 10, 306-316, https://doi.org/10.1175/1520-0442(1997)010<0306: SPOWMC $>2.0 . \mathrm{CO} ; 2$.

Jones, D. C., 2020: DanJonesOcean/ecco_v4_r2_config: Initial release. Zenodo, accessed 9 January 2020, https://doi.org/ 10.5281/zenodo.3602900.

— , A. J. S. Meijers, E. Shuckburgh, J.-B. Sallée, P. Haynes, E. K. McAufield, and M. R. Mazloff, 2016: How does Subantarctic mode water ventilate the southern hemisphere subtropics? J. Geophys. Res. Oceans, 121, 6558-6582, https://doi.org/ 10.1002/2016JC011680.

— , G. Forget, B. Sinha, S. A. Josey, E. J. D. Boland, A. J. S. Meijers, and E. Shuckburgh, 2018: Local and remote influences on the heat content of the Labrador sea: An adjoint sensitivity study. J. Geophys. Res. Oceans, 123, 2646-2667, https://doi.org/10.1002/2018JC013774.

— , E. Boland, A. J. Meijers, G. Forget, S. A. Josey, J.-B. Sallee, and E. Shuckburgh, 2019: Heat distribution in the Southeast Pacific is only weakly sensitive to high-latitude heat flux and wind stress. J. Geophys. Res. Oceans, 124, 8647-8666, https:// doi.org/10.1029/2019JC015460.

Kara, A. B., P. A. Rochford, and H. E. Hurlburt, 2000: An optimal definition for ocean mixed layer depth. J. Geophys. Res., 105, 16 803-16821, https://doi.org/10.1029/2000JC900072.

Karsten, R., and J. Marshall, 2002: Testing theories of the vertical stratification of the ACC against observations. Dyn. Atmos. Oceans, 36, 233-246, https://doi.org/10.1016/S0377-0265(02) 00031-3.

Katsumata, K., and M. Fukasawa, 2011: Changes in meridional fluxes and water properties in the Southern Hemisphere subtropical oceans between 1992/1995 and 2003/2004. Prog. Oceanogr., 89, 61-91, https://doi.org/10.1016/j.pocean.2010.12.008.

Khatiwala, S., F. Primeau, and T. Hall, 2009: Reconstruction of the history of anthropogenic $\mathrm{CO} 2$ concentrations in the ocean. Nature, 462, 346-349, https://doi.org/10.1038/nature08526.

Kim, Y. S., and A. H. Orsi, 2014: On the variability of Antarctic circumpolar current fronts inferred from 1992-2011 altimetry. J. Phys. Oceanogr., 44, 3054-3071, https://doi.org/10.1175/ JPO-D-13-0217.1.

Large, W., and S. Yeager, 2009: The global climatology of an interannually varying air-sea flux data set. Climate Dyn., 33, 341-364, https://doi.org/10.1007/s00382-008-0441-3.

Lenton, A., and R. Matear, 2007: Role of the Southern Annular Mode (SAM) in Southern Ocean $\mathrm{CO}_{2}$ uptake. Global Biogeochem. Cycles, 21, GB2016, https://doi.org/10.1029/ 2006 GB002714.
Liu, L., and R. Huang, 2012: The global subduction/obduction rates: Their interannual and decadal variability. J. Climate, 25, 1096-1115, https://doi.org/10.1175/2011JCLI4228.1.

Losch, M., D. Menemenlis, J.-M. Campin, P. Heimbach, and C. Hill, 2010: On the formulation of sea-ice models. Part 1: Effects of different solver implementations and parameterizations. Ocean Modell., 33, 129-144, https://doi.org/10.1016/ j.ocemod.2009.12.008.

Lovenduski, N., and T. Ito, 2009: The future evolution of the Southern Ocean CO2 sink. J. Mar. Res., 67, 597-617, https:// doi.org/10.1357/002224009791218832.

Lumpkin, R., and K. Speer, 2007: Global ocean meridional overturning. J. Phys. Oceanogr., 37, 2550-2562, https://doi.org/ 10.1175/JPO3130.1.

Luyten, J., J. Pedlosky, and H. Stommel, 1983: The ventilated thermocline. J. Phys. Oceanogr., 13, 292-309, https://doi.org/ 10.1175/1520-0485(1983)013<0292:TVT>2.0.CO;2.

Marotzke, J., R. Giering, K. Zhang, D. Stammer, C. Hill, and T. Lee, 1999a: Construction of the adjoint MIT ocean general circulation model and application to Atlantic heat transport sensitivity. Rep. 63, 49 pp., http://web.mit.edu/cgcs/www/ MIT_CGCS_Rpt63.pdf.

,-- K. Q. Zhang, D. Stammer, C. Hill, and T. Lee, 1999b: Construction of the adjoint MIT ocean general circulation model and application to Atlantic heat transport sensitivity. J. Geophys. Res., 104, 29 529-29 547, https://doi.org/10.1029/ 1999JC900236.

Marshall, J., and K. Speer, 2012: Closure of the meridional overturning circulation through Southern Ocean upwelling. Nat. Geosci., 5, 171-180, https://doi.org/10.1038/ngeo1391.

Mazloff, M., P. Heimbach, and C. Wunsch, 2010: An eddy-permitting Southern Ocean state estimate. J. Phys. Oceanogr., 40, 880-899, https://doi.org/10.1175/2009JPO4236.1.

McAufield, E. K., 2019: Lagrangian study of the Southern Ocean circulation. Ph.D. thesis, University of Cambridge, 345 pp., https://doi.org/10.17863/CAM.36004.

McDougall, T., and P. Barker, 2011: Getting started with TEOS-10 and the Gibbs Seawater (GSW) Oceanographic Toolbox. SCOR/IAPSO WG127, 28 pp., http://www.teos-10.org/pubs/ Getting_Started.pdf.

Meijers, A. J. S., 2014: The Southern Ocean in the Coupled Model Intercomparison Project phase 5. Philos. Trans. Roy. Soc. London, 372A, 20130296, https://doi.org/10.1098/rsta.2013.0296.

_ I. Cerovečki, B. A. King, and V. Tamsitt, 2019: A see-saw in Pacific Subantarctic mode water formation driven by atmospheric modes. Geophys. Res. Lett., 48, 13 152-13 160, https:// doi.org/10.1029/2019GL085280.

Morrison, A., A. Hogg, and M. L. Ward, 2011: Sensitivity of the Southern Ocean overturning circulation to surface buoyancy forcing. Geophys. Res. Lett., 38, L14602, https://doi.org/ 10.1029/2011GL048031.

Musgrave, D., 1990: Numerical studies of tritium and helium-3 in the thermocline. J. Phys. Oceanogr., 20, 344-373, https://doi.org/ 10.1175/1520-0485(1990)020<0344:NSOTAH > 2.0.CO;2.

Naveira Garabato, A. C., L. Jullion, D. P. Stevens, K. J. Heywood, and B. A. King, 2009: Variability of Subantarctic mode water and Antarctic intermediate water in the Drake Passage during the late-twentieth and early-twenty-first centuries. J. Climate, 22, 3661-3688, https://doi.org/10.1175/2009JCLI2621.1.

Primeau, F., and M. Holzer, 2006: The ocean's memory of the atmosphere: Residence-time and ventilation-rate distributions of water masses. J. Phys. Oceanogr., 36, 1439-1456, https:// doi.org/10.1175/JPO2919.1. 
Roemmich, D., J. Church, J. Gilson, D. Monselesan, P. Sutton, and S. Wijffels, 2015: Unabated planetary warming and its ocean structure since 2006. Nat. Climate Change, 5, 240-245, https:// doi.org/10.1038/NCLIMATE2513.

Russell, J., K. Dixon, A. Gnanadesikan, R. Stouffer, and J. Toggweiler, 2006: The Southern Hemisphere westerlies in a warming world: Propping open the door to the deep ocean. J. Climate, 19, 6382-6390, https://doi.org/10.1175/JCLI3984.1.

Sabine, C., and Coauthors, 2004: The oceanic sink for anthropogenic $\mathrm{CO}_{2}$. Science, 305, 367-371, https://doi.org/10.1126/ SCIENCE.1097403.

Sallée, J.-B., and S. Rintoul, 2011: Parameterization of eddy-induced subduction in the Southern Ocean surface-layer. Ocean Modell., 39, 146-153, https://doi.org/10.1016/j.ocemod.2011.04.001.

- K. Speer, S. Rintoul, and S. Wijffels, 2010: Southern Ocean thermocline ventilation. J. Phys. Oceanogr., 40, 509-529, https://doi.org/10.1175/2009JPO4291.1.

_ - R. J. Matear, S. R. Rintoul, and A. Lenton, 2012: Localized subduction of anthropogenic carbon dioxide in the Southern Hemisphere oceans. Nat. Geosci., 5, 579-584, https://doi.org/ 10.1038/ngeo1523.

Sarmiento, J. L., N. Gruber, M. A. Brzezinski, and J. P. Dunne, 2004: High-latitude controls of thermocline nutrients and low latitude biological productivity. Nature, 427, 56-60, https:// doi.org/10.1038/nature02127.

Schmidtko, S., and G. C. Johnson, 2012: Multidecadal warming and shoaling of Antarctic intermediate water. J. Climate, 25, 207221, https://doi.org/10.1175/JCLI-D-11-00021.1.

Sévellec, F., and A. V. Fedorov, 2015: Optimal excitation of AMOC decadal variability: Links to the subpolar ocean. Prog. Oceanogr., 132, 287-304, https://doi.org/10.1016/j.pocean.2014.02.006.

Speer, K., and E. Tziperman, 1992: Rates of water mass formation in the north Atlantic ocean. J. Phys. Oceanogr., 22, 93-104,
https://doi.org/10.1175/1520-0485(1992)022<0093:ROWMFI > 2.0.CO;2.

—- and G. Forget, 2013: Global distribution and formation of mode waters. Ocean Circulation and Climate: A 21st Century Perspective, G. Siedler et al., Eds., Elsevier, 211226.

—, S. Rintoul, and B. Sloyan, 2000: The diabatic deacon cell. J. Phys. Oceanogr., 30, 3212-3222, https://doi.org/10.1175/ 1520-0485(2000)030<3212:TDDC $>2.0 . C O ; 2$.

Talley, L., 2008: Freshwater transport estimates and the global overturning circulation: Shallow, deep and throughflow components. Prog. Oceanogr., 78, 257-303, https://doi.org/10.1016/ j.pocean.2008.05.001.

_ 2013: Closure of the global overturning circulation through the Indian, Pacific, and southern oceans: Schematics and transports. Oceanography, 26, 80-97, https://doi.org/10.5670/ oceanog.2013.07.

Thacker, W. C., and R. B. Long, 1988: Fitting dynamics to data. J. Geophys. Res., 93, 1227-1240, https://doi.org/10.1029/ JC093iC02p01227.

Thompson, A. F., and J.-B. Sallée, 2012: Jets and topography: Jet transitions and the impact on transport in the Antarctic circumpolar current. J. Phys. Oceanogr., 42, 956-972, https:// doi.org/10.1175/JPO-D-11-0135.1.

Trossman, D. S., L. Thompson, S. Mecking, and M. J. Warner, 2012: On the formation, ventilation, and erosion of mode waters in the North Atlantic and Southern Oceans J. Geophys. Res. Oceans, 117, C09026, https://doi.org/ 10.1029/2012JC008090.

Verdy, A., M. R. Mazloff, B. D. Cornuelle, and S. Y. Kim, 2014: Wind-driven sea level variability on the California coast: An adjoint sensitivity analysis. J. Phys. Oceanogr., 44, 297-318, https://doi.org/10.1175/JPO-D-13-018.1. 